[Paper submitted to Quaternary International]

\title{
QUATERNARY GOMPHOTHERES (MAMMALIA: PROBOSCIDEA: GOMPHOTHERIIDAE) FROM THE CONTINENTAL SHELF, PEARL ISLANDS, PANAMA
}

Gary S. Morgan, New Mexico Museum of Natural History, Albuquerque, NM 87104, USA Bruce J. MacFadden, Florida Museum of Natural History, University of Florida, Gainesville, Florida 32611 U SA

Martín Martínez, Museo de Ciencias Naturales de Panama, Panama City, Panama

\section{ABSTRACT}

Fishermen have recovered four Quaternary proboscidean teeth from the continental shelf in the vicinity of the Pearl Islands, about 50 to $80 \mathrm{~km}$ offshore from the southern coast of Panama. Two upper third molars (M3) and one lower third molar (m3) are similar to comparable teeth of the Pleistocene gomphothere Cuvieronius based on the presence of $4 \frac{1}{2}$ to $5 \frac{1}{2}$ lophs/lophids that are either horizontal or slightly inclined to long axis of the tooth and rather complicated enamel with single trefoils, incipient double trefoils, and numerous small accessory cusps. Cuvieronius is also known from the Pleistocene El Hatillo and La Trinidaíta sites from the Azuero Peninsula in Panama. The teeth of Cuvieronius from the Pearl Islands are referred to $C$. hyodon following recent taxonomic revisions indicating a single pan-American species of this genus was present in both North America and South America. The oldest records of Cuvieronius are from early Pleistocene (early Irvingtonian) faunas in El Salvador, Florida, and New Mexico. Cuvieronius 
dispersed to South America in the early Pleistocene during the Great American Biotic Interchange, with the earliest record of $C$. hyodon on that continent from the early to middle Pleistocene (Ensenadan) Tarija fauna in Bolivia. The two late Pleistocene populations of $C$. hyodon in the Neotropical region have a disjunct biogeographic distribution, with the population from southern Mexico and Central America separated from the second population in the Andean highlands of Ecuador, Peru, and Bolivia by a distance of about $1,000 \mathrm{~km}$. The intervening region comprising the lowland tropics of northern South America was populated by the gomphothere Notiomastodon during the late Pleistocene, although Notiomastodon is also known from Andean localities in Ecuador and Peru. Two of the Cuvieronius teeth from the Pearl Islands were recovered in nets by shrimp fisherman from depths of about $90 \mathrm{~m}$, likely indicating they date to the Last Glacial Maximum between 30 and $15 \mathrm{ka}$, when sea level was as much as $120 \mathrm{~m}$ lower than present and the Gulf of Panama was dry land. These teeth represent the first record of late Pleistocene fossils of terrestrial mammals from the continental shelf in Central America.

\section{Introduction}

We report four proboscidean teeth of Late Quaternary age from the continental shelf in the vicinity of the Pearl Islands (Archipiélago de las Perlas) in the Gulf of Panama (Golfo de Panamá), offshore from the southern coast of Panama in the eastern Pacific Ocean (Fig. 1). The Pearl Islands fossils consist of three complete teeth and a fourth partial tooth of gomphotheres (Proboscidea: Gomphotheriidae). Two of the teeth were collected in nets by fisherman from the shallow waters of the Gulf of Panama. Although proboscideans of the gomphothere genus Cuvieronius are among the most common mammals from Pleistocene fossil sites elsewhere in 
Central America (Cisneros, 2005; Lucas and Alvarado, 2010), only two records of Cuvieronius were known previously from Panama, both from the Azuero Peninsula (Gazin, 1957; Pearson, 2005; Lucas, 2014). To our knowledge, the Pearl Islands gomphothere fossils represent the first records of Pleistocene mammals from the continental shelf in Central America or Mexico. These teeth almost certainly date to a glacial period, when sea levels were as much as $120 \mathrm{~m}$ below the present level and the shallow Gulf of Panama was mostly dry land. The two teeth from the Pearl Islands with the best provenance were recovered from a depth of about $90 \mathrm{~m}$, suggesting they date to the late Pleistocene, probably during the Last Glacial Maximum between 30 and $15 \mathrm{ka}$. We provide descriptions and measurements of Pearl Islands gomphothere teeth, compare them to other gomphotheres from Central America, Mexico, Texas, Florida, and South America, and discuss their taxonomy, biogeography and provenance.

\section{Materials and methods}

The four teeth of gomphotheres from the vicinity of the Pearl Islands are housed in three museums. Two teeth are on display in the Museo de Ciencias Naturales, Panama City, Panama (MCNP); one tooth is on display in the Biomuseo, Panama City, Panama, but is originally from the paleontology collection of the Smithsonian Tropical Research Institute, Center for Tropical Paleontology and Archaeology (STRI/CTPA); and one tooth is in the vertebrate paleontology collection of the U. S. National Museum of Natural History (USNM), Smithsonian Institution, Washington, DC. We also examined comparative specimens of Cuvieronius in the vertebrate paleontology collection of the Florida Museum of Natural History at the University of Florida (UF) in Gainesville. 
In addition to the museum acronyms listed above, other abbreviations used in this paper are: $\mathrm{ka}(\mathrm{kilo}-\mathrm{anna}=$ thousands of years); Ma (Mega-anna $=$ millions of years); GABI (Great American Biotic Interchange); LF (Local Fauna); LGM (Last Glacial Maximum); NALMA (North American land mammal age); SALMA (South American land mammal age). The abbreviations for tooth positions are standard for mammals, with upper case letters for upper teeth and lower case letters for lower teeth. For example, M3 is an upper third molar and m2 is a lower second molar. Descriptions of the teeth follow the dental terminology for gomphotheriid proboscideans (Savage, 1955; Tobien, 1973; Lambert, 2007). In discussing gomphotheres from Mexico and Central America, we use the geographic names Mesoamerica, Middle America, and tropical North America interchangeably to refer to this geographic region. We prefer the term "gomphothere" for members of the proboscidean family Gomphotheriidae, rather than the terms "mastodon" or "mastodont" which are used for members of both the Gomphotheriidae and Mammutidae. We restrict usage of mastodon to the Mammutidae, including the American mastodon Mammut americanum.

We follow current usage in recognizing the Pliocene/Pleistocene boundary at $2.58 \mathrm{Ma}$, corresponding to the onset of Northern Hemisphere glaciation and the boundary between the Gauss and Matuyama geomagnetic chrons (Gibbard et al., 2010). The ages, boundaries, and faunal characterizations of the Pliocene and Pleistocene land mammal ages follow Bell et al. (2004) for the Blancan, Irvingtonian, and Rancholabrean NALMA in North America and Marshall et al. (1984) and Cione and Tonni (1995) for the Uquian (= Marplatan), Ensenadan, and Lujanian SALMA in South America.

\section{Regional setting}


Three complete teeth and one partial tooth of gomphotheres are reported from the shallow waters of the Gulf of Panama near the Archipiélago de las Perlas or Pearl Islands, about 75-100 km southeast of Panama City, Panama (Fig. 1). Based on the available provenance, all four teeth are derived from the continental shelf from depths as great as $90 \mathrm{~m}$. At least two of teeth, and probably all four teeth, were found by fishermen in shrimp nets that were dragged along the sea floor. For the two teeth known to have been caught in fisherman's nets, the depths should be considered approximations since we do not know the exact distances or depths over which the nets were dragged. Not surprisingly, considering the conditions of their discovery, these specimens have imprecise localities and lack geological data or other associated faunal remains. One tooth was found south of Isla del Rey, the largest of the Pearl Islands, two teeth were found near Isla de San José, and a fourth tooth was found west of Isla de San José and Isla de Pedro González (Fig. 1). The area of the Pearl Islands and continental shelf circumscribed by the localities for these fossils is between approximately $8^{\circ} 10^{\prime}$ and $8^{\circ} 21^{\prime}$ North latitude and $78^{\circ} 40^{\prime}$ and $79^{\circ} 12^{\prime}$ West longitude. These sites range from 50 to $80 \mathrm{~km}$ offshore from the southern coast of Panama. The latitude of the Pearl Islands proboscidean teeth would make them among the southernmost Quaternary fossils known from Central America. Specimens of Cuvieronius and other mammals from Late Quaternary sites on the Azuero Peninsula of Panama were found slightly farther south, between $7^{\circ}$ and $8^{\circ}$ North latitude, about $200 \mathrm{~km}$ southwest of the Pearl Islands (Gazin, 1957; Lucas, 2014).

\subsection{Previous records of Quaternary proboscideans from Panama}


There are three published records of Pleistocene proboscideans from Panama. Gazin (1957) described the giant ground sloth Eremotherium from the El Hatillo site (Fig. 1, site 2), located about 2 km west of Pesé in Herrera Province on the Azuero Peninsula in south-central Panama $\left(7^{\circ} 55^{\prime} \mathrm{N}, 80^{\circ} 38^{\prime} \mathrm{W}\right)$, and also discussed an associated vertebrate fauna of about 10 species, including a proboscidean. Gazin (1957) tentatively identified the El Hatillo proboscidean as Cuvieronius hyodon, recognized at that time as a South American species. Pearson (2005) identified a tooth fragment, three vertebrae, and tibia of Cuvieronius from the La Trinidaíta site (Fig. 1, site 1), located just west of El Hatillo about 9 km west of Pesé (754' N, $80^{\circ} 42^{\prime}$ W). Pearson referred the gomphothere material from La Trinidaíta to C. tropicus, generally recognized as the North American species of Cuvieronius (see taxonomic discussion below). Lucas (2014) reexamined the late Pleistocene mammalian fauna from El Hatillo. He described and illustrated the gomphothere teeth previously mentioned by Gazin (1957), referring these specimens to $C$. hyodon. The El Hatillo and La Trinidaíta sites are located at an elevation of about $100 \mathrm{~m}$ on the Azuero Peninsula about $30 \mathrm{~km}$ inland from the Bahía de Parita, a bay in the western Gulf of Panama. Brief descriptions of the gomphotheres from El Hatillo and La Trinidaíta are presented below, after the description of the Cuvieronius teeth from the Pearl Islands.

\subsection{Pearl Islands gomphothere localities}

The Pearl Islands proboscidean tooth with the most complete data is a right M3 (USNM 421665), dredged from a depth of 50 fathoms (about 300 feet or $90 \mathrm{~m}$ ) by a shrimp trawler belonging to a Mr. Earnist. A cast of this tooth was donated to the U. S. National Museum of 
Natural History through Robert N. Stewart, formerly a geologist with the U. S. Panama Canal Zone. Although the locality data with the specimen state that the tooth was found "... south of the Pearl Islands of Panama” the coordinates associated with the fossil ( $8^{\circ} 21^{\prime}$ North latitude, $79^{\circ} 12^{\prime}$ West longitude) place the locality on the continental shelf just west of the Pearl Islands, about 8 km west of Isla de Pedro González and 10 km northwest of Isla de San José (Fig. 1, site 3).

Two teeth on display in the Museo de Ciencias Naturales, Panama City, Panama (MCNP 1 and MCNP 2) were collected by J. V. Delgado from “Isla de San José, Archipiélago de las Perlas" according to the specimen label associated with these teeth (Fig. 1, site 4). Although the locality information does not specify that the fossils were recovered by fisherman, the two MCNP teeth from Isla de San José were collected underwater in a marine environment based on the presence of marine epiphytic invertebrates adhering to the ventral surface of each tooth, including oysters, gastropods, small solitary corals, and bryozoans. The occurrence of the marine epiphytes only on the ventral or underside of the tooth (the roots are broken away) suggests that the teeth were both resting with the occlusal or crown surface facing down on the sea floor. The teeth are a grayish black in color and are heavily mineralized, whereas the attached invertebrates are white and appear to be modern, not fossil.

A fourth gomphothere tooth from the Pearl Islands, a right m3, was originally donated to the collection of Smithsonian Tropical Research Institute/Center for Tropical Paleontology and Archaeology (STRI/CTPA) in Panama in about 2008. The tooth is now on display in the recently opened Biomuseo in Panama City, Panama. On the basis of information provided by the collector to Richard Cooke, an anthropologist with STRI/CTPA, the tooth was recovered by the captain of a shrimp boat trawling in about 50 fathoms of water south of Isla del Rey (Fig. 1, site 
5). This is about the same depth (about 300 feet or $90 \mathrm{~m}$ ) from which the tooth west of Isla de Pedro González and Isla de San José was recovered.

\section{Results}

\subsection{Descriptions of gomphothere teeth from Panama}

\subsubsection{Right m3 from Isla del Rey, STRI/CTPA Collection (now on display in the Biomuseo)}

A right $\mathrm{m} 3$ from south of Isla del Rey in the Pearl Islands, originally in the STRI/CTPA Collection (STRI/CTPA 1) and now on display in the Biomuseo, is very well preserved with an intact crown, but with the roots broken off (Fig. 2). The fossil tooth is black in color and heavily mineralized. It is completely unworn and lacks an interdental wear facet on its anterior margin where the tooth presumably would have contacted the $\mathrm{m} 2$. The enamel on the basal half of the crown is highly striated or crenulated, whereas the proximal half of each major cusp is essentially smooth. The tooth also has numerous small to very small, rounded, accessory cusps or cuspids distributed throughout the crown. The total number of all major and accessory cusps on this tooth is about 60 (after Mothé and Avilla, 2015). Cement is absent. The tooth can be identified as a lower $\mathrm{m} 3$ on the basis of the presence of more than three complete lophids and the gentle labial curvature from anterior to posterior. Upper M3s also have four or more lophs but are essentially straight from anterior to posterior, not curved. As in mammalian dental terminology in general, lower teeth have dental terms ending in -id whereas upper teeth do not. For instance, a loph on an upper tooth would be a lophid on a lower tooth. 
The m3 has five complete lophids and several small cuspids on the posterior edge of the tooth that could be considered a sixth lophid, but generally are regarded as a partial or half lophid, for a total of $5 \frac{1}{2}$ lophids. The lack of an interlophid between the fifth lophid and the small cuspids on the posterior edge of the m3 suggests that these cuspids could also be considered the distal or posterior cingulum, rather than a partial lophid. The four anterior lophids extend across the entire width of the tooth and are angled slightly posteriorly from the lingual to the labial margin. Each of these four lophids consists of two large conical conids, one lingual, one labial, connected at the midline by from one to three small, rounded, accessory conulids. On each lophid, the lingual conid is located somewhat anterior to the posterior conid. Lophid 5 is different in size and shape from the anterior four lopids. It is much narrower and strongly curved rather than essentially straight, convex anteriorly, concave posteriorly. The larger lingual and labial conids are positioned posteriorly to the two small rounded midline conulids. Posterior to lophid 5, on the posterior margin of the tooth, is a small half lophid consisting of four tiny cuspids that are essentially horizontal in orientation. These cuspids could also be considered the posterior cingulum.

Trefoiling is present on lophids 1-4, consisting of a well-developed ridge extending posteriorly from the primary labial cusp, just labial to the midline of the tooth. The individual trefoils consist of two to three small rounded cuspids that would have coalesced with wear. There is minor secondary or double trefoiling, consisting of one or two small cuspids extending posteriorly from the primary lingual conid. The valleys separating lophids 1-5 are deep, extending two-thirds of the distance to the base of the crown, interrupted only by the trefoils extending posteriorly from the labial conid of each lophid. The valleys are not impeded by the smaller lingual trefoils, except between lophids 4 and 5. The $\mathrm{m} 3$ has several weak cingula, the 
most prominent of which is located along the anterior margin of the tooth. The anterior cingulum consists of an elliptical cuspid at the midline connected to a beaded ridge of tiny cuspids that extends almost to the labial edge of the tooth. A fairly well-developed cingulum is located on the labial edge of lophid 4 near the base of the crown. It has an anteroposterior orientation and consists of a beaded ridge of tiny cuspids. There is also a very weak cingulum near the base of the crown on the labial margin of lophid 3 that could probably be considered an anterior extension of the better developed cingulum labial to lophid 4.

\subsubsection{Right M3 and partial right $\mathrm{m} 2 / \mathrm{m} 3$ from Isla de San José, MCNP Collection}

A right M3 from the vicinity of Isla de San José in the Pearl Islands in the MCNP Collection (MCNP 1) is well preserved (Fig. 3). The crown is intact but the roots have been broken off. This tooth is nearly unworn, except for a slight hint of wear on the anterolabial cone on loph 1 . The enamel on the proximal half of the crown is relatively smooth, whereas the enamel is more heavily striated on the basal portion of the crown. The tooth is a right upper M3 composed of five complete lophs and a sixth partial loph for a total of 51/2 lophs. The total number of all major and accessory cusps on this tooth is about 45 (after Mothé and Avilla, 2015). The first three lophs are essentially horizontal relative to the long axis of the tooth, whereas lophs 4 and 5 are angled noticeably posteriorly from the anterolingual to the posterolabial portion of the lophs. Although there is some variation, the four anterior lophs consist of a large conical lingual cone and a somewhat smaller rounded labial cone, joined at the midline by a third rounded accessory conule that is nearly as large as the labial cone. The midline conule is separated from the larger lingual cone by a noticeable valley but is more closely appressed to the 
labial cone of similar size, giving an almost "twinned" appearance. Loph 5 has a large conical lingual cone located anteriorly, separated by a valley from two small rounded midline accessory conules that are separated by a valley from a rounded labial cone. The labial cone is smaller than the lingual cone and positioned considerably farther posteriorly. The lingual cone is positioned progressively more anteriorly relative to the labial cone from the front to the back of the tooth, especially on lophs 4 and 5. The last half loph consists of a rather large, conical midline conule located almost on the posterior margin of the tooth and a smaller rounded conule located in a more anterolingual position on the lingual margin.

The valleys between the lophs are deep and wide between the labial halves of the lophs, but are shallower and much narrower lingually. There are small cusps located at the base of the valleys, on the posterior surfaces of the lophs, and on the posterior margin at the base of the crown. The primary trefoils extend posteriorly from the large lingual cone on each loph just lingual to the midline, and consist of from one to three small cusps that are unworn. The trefoils are most prominent on lophs 1 and 2, weak on lophs 3 and 4, and absent on loph 5. An anterior cingulum consisting of a low beaded ridge composed of very small cusps extends from the base of the primary lingual cone to the labial margin of the tooth.

A second tooth from near Isla de San José in the MCNP Collection (MCNP 2) is the anterior half to two-thirds of a right $\mathrm{m} 2$ or $\mathrm{m} 3$ (Fig. 4). The posterior portion of the tooth is broken off, and thus it is not possible to determine the exact number of lophids present or the tooth position. The two anterior lophids are complete, the posterior lophid or lophid 3 is broken along its posterior face. This is the only tooth in the Pearl Islands sample that shows a substantial amount of wear. There is a prominent interdental wear facet on the anterior margin of the tooth where it would have contacted the next tooth anterior (either $\mathrm{m} 1$ or $\mathrm{m} 2$ ). There is a well- 
developed anterior cingulum anterior to the labial portion of lophid 1, consisting of a large rounded cusp anterior and ventral to the main conid and then extending to the labial margin of the tooth as a low, beaded ridge of tiny cusps. The labial edge of the tooth has numerous small cusps at the base of the crown. The enamel of this tooth is very thick, from 5 to $6 \mathrm{~mm}$ in thickness.

On each lophid the lingual conid is higher and the labial conid is more heavily worn. Lophids 1 and 2 each have large lingual and labial conids connected at the midline by two small, rounded accessory conulids of similar size. Each lophid has a well-developed trefoil that extends posteriorly from the labial conid, just labial to the midline. The trefoils are "club-shaped" with the rounded portion oriented posteriorly. Lophids 2 and 3 also have smaller anterior extensions of the trefoils on the labial conids. There is also minor secondary or double trefoiling, consisting of single, small rounded cusps on the posterior face of the lingual portion of lophids 1 and 2 , just lingual to the midline. These cusps would appear as small trefoils in later wear stages. The valleys between lophids 1 and 2 and 2 and 3 are deep both lingually and labially, but are interrupted along the midline by the primary and secondary trefoils.

\subsubsection{Right M3 from west of Isla San José and Isla de Pedro González, USNM Collection}

A right M3 in the U. S. National Museum of Natural History collection, Smithsonian Institution (USNM 421665) from near Isla San José and Isla de Pedro González in the Pearl Islands is complete and virtually unworn, with just a slight amount of wear on the labial portion of the first loph (Fig. 5). The tooth consists of four complete lophs and a half loph at the posterior edge of the tooth for a total of $4 \frac{1}{2} 2$ lophs. The four complete lophs, as well as the 
posteriormost half loph, are essentially horizontal to the long axis of the tooth. Lophs $1-4$ consist of a large, rounded cone lingually and an anteroposteriorly compressed ridge composed of from three to six smaller rounded cusps labially. The large lingual cone comprises about $40 \%$ the width of each loph, whereas the labial ridge comprises the remaining $60 \%$ of the width. The posteriormost portion of the M3 containing loph 5 (or half loph) is constricted transversely. This loph is about half the width of the four anterior lophs, and consists of two rather large, rounded cusps of similar size, one lingual, one labial.

The enamel on the labial and lingual edges of the lophs of USNM 421665 is heavily striated or crenulated from the base of the crown almost to the tips of the crowns. Besides the major lophs and cones, the crown of the tooth possesses numerous tiny cusps, concentrated in the valleys between the lophs and on the posterior faces of the labial portions of the lophs. The total number of all major and accessory cusps on this tooth is about 48 (after Mothé and Avilla, 2015). One or two small, rounded cusps extending both anteriorly and posteriorly from the lingual cone on lophs $2-4$, just lingual to the midline, would have worn into trefoils. Loph 1 has only the posterior portion of the trefoil, consisting of two small rounded cusps. All four lophs have several small cusps anterior and posterior to the labial portion of the loph, just labial to the midline, that would have worn into small secondary or double trefoils. The valleys separating the major lophs are wide and deep, interrupted only by the primary trefoils just lingual to the midline. The M3 has two prominent cingula, one on the anterior margin of the tooth and another on the posterior margin. The anterior cingulum consists of at least eight small cusps in a horizontal row that form a low, beaded ridge at the base of the crown immediately anterior to loph 1 . The posterior cingulum is composed of at least ten tiny cusps at the base of the crown 
that extend from the posterolabial corner of loph 5 around the posterior margin of the tooth to a position labial to the anterior edge of loph 5.

\subsubsection{Gomphotheres from El Hatillo and La Trinidaíta, Panama}

In addition to the fossils from the Pearl Islands, there are two other records of the gomphothere Cuvieronius from Panama. Gazin (1957, p. 346-347) mentioned several specimens from the El Hatillo site in the Azuero Peninsula (Fig. 1, site 2), including “...associated skeletal portions of a single individual of the mastodon Cuvieronius... including two badly worn last molars and sections of tusk." He noted that this specimen was "...characterized by tusks having enamel developed in a spiral form.” We examined several specimens of Cuvieronius from El Hatillo in the USNM collection, including a lower third molar (m3), a partial tusk, an ulna, and a tibia. The m3, cataloged under the number USNM 540665, is so heavily worn that very little of the occlusal morphology remains; however, this specimen clearly possesses five lophids which is similar to the $\mathrm{m} 3$ from south of Isla del Rey. Measurements of the $\mathrm{m} 3$ from El Hatillo are

presented in Table 1. Lucas (2014) illustrated and described the m3 of C. hyodon from El Hatillo (USNM 540665). More informative is a partial upper tusk from El Hatillo that exhibits the spiraled enamel band characteristic of Cuvieronius. From the La Trinidaíta site, also in the Azuero Peninsula (Fig. 1, site 1), Pearson (2005) referred a tooth fragment, complete tibia, several vertebrae, and a proximal rib to Cuvieronius tropicus.

\subsection{Comparisons of gomphothere teeth from the Pearl Islands with teeth of Cuvieronius from} Mesoamerica, temperate North America, and South America 
Morphological comparisons among the four gomphothere teeth from the Pearl Islands indicate that either one highly variable species or two different species are represented. The most revealing comparisons are between two right M3s from near Isla San José. These two teeth were collected in the same general area, but differ in several important morphological characters. Both teeth are almost totally unworn. One M3 (USNM 421665; Fig. 5) has 41/2 lophs that are essentially horizontal to the long axis of the tooth with wide valleys between the lophs. A second M3 (MCNP 1; Fig. 3) has 51/2 lophs that form an angle to the long axis of the tooth (the lingual portion of the loph is located distinctly anterior to the labial portion) and the valleys between the lophs are narrow especially between the lingual cones. However, both of these M3s have a similar number of total cusps (major cusps plus accessory cusps; after Mothé and Avila, 2015), 45 in the MCNP tooth, 48 in the USNM tooth. A lower m3 from the Pearl Islands (STRI/CTPA 1; Fig. 2) is similar to the MCNP M3, with 51/2 angled lophids, but has a considerably larger number of total cusps (about 60) than either of the other complete third molars from the Pearl Islands.

We compared the gomphothere teeth from the Pearl Islands with descriptions and illustrations of upper and lower third molars (M3/m3) of the Quaternary gomphothere Cuvieronius from both the tropical and temperate regions of North America, including specimens from the following localities: Río Tomayate in El Salvador (Cisneros, 2005); Lago Chapala in the state of Jalisco, west-central Mexico (Lucas, 2008b); the "Valley of Mexico" in central Mexico (Cope, 1884, 1893; Osborn, 1936); Tortugas Mountain in New Mexico (Lucas et al., 1999, 2000); Sinton and Ingleside in Texas (Hay, 1926; Lundelius, 1972); and Leisey Shell Pit, Punta Gorda, and Daytona Beach in Florida (Webb and Dudley, 1995; Lucas, 2008a). 
Measurements of the gomphothere teeth from the Pearl Islands and of the M3s/m3s of Cuvieronius from elsewhere in North America are presented in Table 1. We also made comparisons between the gomphothere teeth from the Pearl Islands and teeth of Cuvieronius hyodon from Tarija, Boliva (Boule and Thevenin, 1920; Mothé and Avilla, 2015). The most common dental morphology of the M3s/m3s among North American specimens of Cuvieronius is to have $4 \frac{1}{2}$ lophs/lophids, single trefoiling, and rather simple enamel with limited development of small accessory cusps. An M3 from the Pearl Islands (USNM 421665) closely matches the typical dental morphology of Cuvieronius (Fig. 5). Two other complete teeth from the Pearl Islands, an m3 and an M3 (Figs. 2, 3), have 51/2 lophs/lophids, incipient double trefoiling, and a somewhat more complex enamel pattern.

Cisneros (2005) illustrated six mandibles with m3s of Cuvieronius from Río Tomayate, El Salvador, although he did not provide measurements of these specimens. Cisneros described the m3s from Río Tomayate as having 4⿺辶2 to 5 angular lophids, single trefoiling, and simple enamel. Several of the El Salvador specimens have a well-developed $5^{\text {th }}$ lophid on $\mathrm{m} 3$, but none has 51/2 lophids. Cisneros also noted that several isolated upper tusks from Río Tomayate exhibited a spiral enamel band. A sample of upper and lower third molars of Cuvieronius from Lago Chapala, Mexico, representing at least five individuals (Lucas, 2008b), overlap in morphology and size with the teeth from the Pearl Islands. Most of the specimens from Lago Chapala have 41/2 lophs/lophids on M3/m3 (four complete lophs/lophids and one or two small posterior midline cusps/cuspids constituting a $1 \frac{1}{2}$ loph/lophid), single trefoiling, and a rather simple enamel pattern with limited plications. However, one of the illustrated m3s from Lago Chapala (Lucas, 2008b, fig. 3D) is similar to the $\mathrm{m} 3$ from the Pearl Islands in possessing 51/2 lophids. In his description of the type specimen of Cuvieronius (= Dibelodon) tropicus from 
Mexico, a mandible with m2-m3, Cope $(1884$, p. 7) stated that "Reference to Von Meyer's figure [1867] shows that the last inferior molar [m3] has five well-developed cross-crests and a heel.” Von Meyer's illustration of the specimen Cope later designated the type of $C$. tropicus was reproduced by Osborn (1936, fig. 513). Even though most M3s/m3s of Cuvieronius from North America have $4 \frac{1}{2}$ or 5 lophs/lophids, the type specimen of $C$. tropicus has $5 \frac{1}{2}$ lophids ("five ...cross-crests and a heel"), in agreement with an M3 and an m3 from the Pearl Islands.

Samples of Cuvieronius teeth from Pleistocene sites in temperate North America, including New Mexico, Texas, and Florida, exhibit the same general dental morphology as described above for Cuvieronius from Mexico and Central America, including the teeth from the Pearl Islands. As with the Mesoamerican Cuvieronius, there is considerable dental variation in the temperate North American sample. Specimens of Cuvieronius from the early Pleistocene (early Irvingtonian) Tortugas Mountain Fauna in New Mexico include a palate with two M3s having 4 lophs and a single posterior midline cusp and a lower jaw from a different individual with an $\mathrm{m} 3$ that has four lophids and two well-developed cuspids on the posterior margin that could be interpreted as an incipient $5^{\text {th }}$ lophid or half lophid, or as a posterior cingulum (Lucas et al., 1999, 2000). An associated maxilla and mandibles of Cuvieronius from the late Pleistocene (Rancholabrean) Sinton Local Fauna (LF) in southern Texas have 51/2 lophs/lophids on the M3/m3 (Hay, 1926). An isolated m3 of Cuvieronius from the Rancholabrean Ingleside LF in southern Texas also has 51/2 lophids (Lundelius, 1972). The Cuvieronius teeth from Texas closely resemble the M3 and $\mathrm{m} 3$ from the Pearl Islands with 51/2 lophs/lophids. The Florida sample of Cuvieronius includes isolated M3s from the early Irvingtonian Leisey Shell Pit and Punta Gorda LFs and two mandibles with m3s from the Rancholabrean Daytona Beach LF. The M3s from Leisey and Punta Gorda have four lophs with a small midline cusp on the posterior midline and 
the two m3s from Daytona Beach have four lophids with a fifth (half) lophid posteriorly consisting of two small cusps. The M3s of Cuvieronius from Leisey and Punta Gorda are similar to the simpler of the two M3s from the Pearl Islands (USNM 421665).

We also made comparisons of the gomphothere teeth from the Pearl Islands with a large sample of Cuvieronius teeth from the early to middle Pleistocene (Ensenadan SALMA) fauna from Tarija, Bolivia, based on illustrations and descriptions of the Bolivian sample in Boule and Thevenin (1920) and Mothé and Avilla (2015), as well as specimens from Tarija in the UF/FLMNH collection. Mothé and Avilla (2015) illustrated two lower m3s of C. hyodon from Tarija, one with a simple enamel pattern and one with a complex enamel pattern. These two teeth encompass much of the dental variation observed in Cuvieronius teeth from the Pearl Islands, elsewhere in Central America, Mexico, and temperate North America. The Tarija teeth have 41/2 to 5 lophids and range from a very simple enamel pattern with little development of accessory cusps to a more complex pattern with numerous accessory cusps.

Mothé and Avilla (2015) proposed a method for evaluating the enamel complexity of the third molars (M3/m3) of South American gomphotheres by counting the total number of cusps, including both major cusps and accessory cusps. They determined that the third molars of South American Cuvieronius have between 33 and 60 total cusps, with most specimens ranging from 40 to 53. Two complete upper third molars (M3s) of gomphotheres from the Pearl Islands are within the average range of total cusps for Cuvieronius third molars from South America, with 45 cusps in MCNP 1 and 48 in UNSM 421665. The other complete third molar from the Pearl Islands, a lower m3 (STRI/CTPA 1), has considerably more complex enamel, with about 60 total cusps (ranging from 58 to 65 cusps, depending on whether or not the tiniest accessory cusps are counted). The $\mathrm{m} 3$ from the Pearl Islands agrees more closely with the total cusp count for 
Notiomastodon third molars from South America, which have between 35 and 82 total cusps, with most specimens ranging from 46 to 58. However, Mothé and Avilla (2015) noted there is considerable overlap in total cusp count between Cuvieronius and Notiomastodon and, with the exception of extremely complex teeth of Notiomastodon, the number of cusps on the last molars is not valid to differentiate these two genera.

Lambert and Shoshani (1998) observed that North American samples of Cuvieronius exhibit a remarkable range of variation in cheek tooth morphology, including four and a fraction to five and a fraction lophs, single to double trefoiling, and ptychodont enamel (numerous small accessory cusps, often with highly striated enamel) to simple aptychodont enamel. Much of the range of dental variation in the Cuvieronius teeth from Central America, Mexico, New Mexico, Texas, and Florida, as well as Tarija, Bolivia, can be duplicated in the small sample of teeth from the Pearl Islands. Overall, there is substantial variation in dental features both within and between North American samples of Cuvieronius. Measurements in Table 1 indicate that the Cuvieronius teeth from the Pearl Islands fall within the observed size range for the majority of Cuvieronius third molars from North America. There are several notably large M3s/m3s in the North American sample, including specimens from the early Irvingtonian Tortugas Mountain Fauna in New Mexico and the Rancholabrean Ingleside and Sinton LFs in Texas (Table1). Despite the considerable range of variation in dental morphology observed in the Pearl Islands teeth, we tentatively refer all of these specimens to Cuvieronius hyodon, the common late Pleistocene gomphothere species from Central America. See taxonomic discussion below for our usage of C. hyodon rather than C. tropicus for North American Cuvieronius.

\subsection{Age of Cuvieronius from the Pearl Islands}


We did not attempt to obtain a radiocarbon date on the teeth from the Pearl Islands because all of the specimens have been submersed in saltwater for a long period of time, probably since the end of the Pleistocene, if not earlier. According to Ron Hatfield from Beta Analytic (in litt. October 8, 2013), "Tooth proteins can be leached away if submersed in water for long periods of time. Given the very long time that these samples were submerged it's likely that any tooth proteins have been removed." No other mammal fossils have been found in association with the Cuvieronius teeth from the Pearl Islands that might provide additional information on their biochronology. The identification of the teeth as Cuvieronius restricts their age to between the early Irvingtonian and late Rancholabrean ( 1.6 Ma-10 ka). As discussed below, most records of Cuvieronius from Central America are late Pleistocene in age, with the exception of two early Pleistocene faunas from El Salvador (Webb and Perrigo, 1984; Cisneros, 2005).

The most useful information on the age of the Cuvieronius teeth from the Pearl Islands comes from their provenance. All four of the teeth were found in a marine environment, and the two specimens with the most complete data were recovered in shrimp nets from a depth of approximately 50 fathoms $(=300 \mathrm{feet}=\sim 90 \mathrm{~m})$. All four of the teeth are in excellent condition, although lacking roots, suggesting that they were not transported a long distance and were probably buried for a considerable period of time and not subjected to movement by tides or currents. Two of the teeth have attached specimens of modern epiphytic marine invertebrates (see Figs. 3B, 3C, 4B), indicating that the specimens rested on the sea floor for at least a short period of time, although not long enough to have suffered much damage. If the teeth were not transported a long distance from where they were recovered on the sea floor in the Gulf of 
Panama, then the depth at which they were found ( 90 m) should give a good indication of sea level at the time the fossils were deposited, considering that the continental shelf must have been dry land for the gomphotheres to have survived there.

Precise data pertaining to Pleistocene sea levels are only available for about the past 130 ka, covering the last glacial-interglacial cycle or Marine Isotope Stages (MIS) 1-5 (Lambeck et al., 2002). According to several proxies of sea level change, including uplifted coral reefs with uranium-series dates, estimated ice volumes, and oxygen $\left({ }^{18} \mathrm{O} /{ }^{16} \mathrm{O}\right)$ isotopes from marine microfossils, at only one time in the last $130 \mathrm{ka}$, during the Last Glacial Maximum (LGM) between about 30 and $15 \mathrm{ka}$ (MIS 2), were sea levels as low as $90 \mathrm{~m}$ below current mean sea level (msl) (Lambeck et al., 2002). Sea level reached its lowest level ( 120 m below msl) near the end of the LGM about $19 \mathrm{ka}$; however, sea level remained approximately $90 \mathrm{~m}$ below msl until about $15 \mathrm{ka}$ (Lambeck et al., 2002). We strongly suspect that the Pearl Islands gomphothere teeth date to the LGM or the latest Pleistocene (late Rancholabrean NALMA), probably between 30 and $15 \mathrm{ka}$, based on the recovery of two of the teeth from depths of approximately $90 \mathrm{~m}$ on the continental shelf in the Gulf of Panama.

\section{Discussion}

\subsection{Taxonomy and systematics of Cuvieronius}

The species-level taxonomy of Cuvieronius in both North America and South America is complex and confusing. Several comprehensive works on North American Pleistocene Proboscidea have identified Cuvieronius only to the generic level (e.g., Kurtén and Anderson, 
1980; Lambert and Shoshani, 1998). Arroyo-Cabrales et al. (2007) noted that three different species names have been applied to this genus in Mesoamerica, C. hyodon, C. oligobunis, and $C$. tropicus. Webb and Dudley (1995) used the oldest available name for a North American species of Cuvieronius, C. tropicus (Cope, 1884), for specimens from the early Pleistocene Leisey Shell Pit and Punta Gorda faunas in Florida. C. tropicus was originally named for a lower jaw from the state of Michoacan in the Valley of Mexico, central Mexico, presumably of late Pleistocene age (Cope 1884). Cope (1893) later named a second species, C. oligobunis, based on a pair of lower jaws from the late Pleistocene Tequixquiac fauna, also from the Valley of Mexico in central Mexico. Webb and Dudley (1995) synonymized C. oligobunis with C. tropicus. Most recent authors (e.g., Ferretti, 2008; Mothé et al., 2013) recognize a single species of Cuvieronius from South America, C. hyodon (Fischer, 1814), the oldest available name for a South American species in this genus.

Until recently, the trend has been to recognize two species of Cuvieronius, C. tropicus from North America and C. hyodon from South America. However, the range of dental variation in samples of $C$. tropicus and $C$. hyodon appears to overlap substantially (Lucas, 2008a; Lucas and Alvarado, 2010). In comparisons of Cuvieronius teeth from Florida, Mexico, Central America, and South America, Lucas (2008a) could find no consistent differences in the dentition, size, or other characters to separate North American Cuvieronius, previously referred to $C$. tropicus, and South American populations of Cuvieronius referred to C. hyodon. The similarity between these two species led Lucas (2008a, 2013) and Lucas and Alvarado (2010) to refer all Cuvieronius from temperate North America and Mesoamerica to C. hyodon (Fischer, 1814), which has priority over C. tropicus (Cope, 1884).

Pending a detailed taxonomic review of all New World Cuvieronius, we recognize a 
single pan-American species in this genus, C. hyodon. A similar situation occurs in late Pleistocene populations of the giant ground sloth Eremotherium, which had been split into North American (E. mirabile) and South American (E. laurillardi) species, until Cartelle and DeIuliis (1995) combined them as the pan-American species E. laurillardi. Cuvieronius and Eremotherium are often associated in Central American Pleistocene faunas, including Panama where these two genera co-occur in the El Hatillo and El Trinidaíta sites (Gazin, 1957; Pearson, 2005; Lucas, 2014). Cisneros (2005) noted the abundance of Cuvieronius in the Irvingtonian Río Tomayate fauna in El Salvador, where at least six individuals occur, together with a skeleton of Eremotherium. Cuvieronius and Eremotherium are two of the most common large mammals in the Rancholabrean Daytona Beach fauna along the Atlantic coast of Florida (Morgan and Hulbert, 1995).

Cuvieronius and another gomphothere genus, Rhynchotherium, appear to be closely related based on the presence of the derived character of the helicoidal (spiral) curvature of the upper tusks, including the enamel band (Lambert and Shoshani, 1998; Lucas and Morgan, 2008). These two genera can be easily distinguished from the morphology of the mandibles. Cuvieronius has a short (brevirostrine) mandibular symphysis and lacks lower tusks, whereas Rhynchotherium has a longer symphysis that is downturned at a $45^{\circ}$ angle or greater and bears a pair of small lower tusks that are rounded to elliptical in cross-section and often have a lateral enamel band. Webb and Perrigo (1984) recommended that the presence (Rhynchotherium) or absence (Cuvieronius) of lower tusks be used as the defining character separating these two genera. In addition, Rhynchotherium has third molars with only 4 or at most $4 \frac{1}{2}$ lophs/lophids and rather simple enamel, whereas Cuvieronius tends to have more complicated teeth with third molars having $4 \frac{1}{2}$ to $5 \frac{1}{2}$ lophs/lophids and enamel with some development of accessory cusps. 
Several late Miocene (Hemphillian NALMA) gomphothere species from Mexico and Central America previously referred to Rhynchotherium, R. blicki (including Aybelodon hondurensis) and $R$. tlascalae (Webb and Perrigo, 1984), are now considered to be advanced species of Gomphotherium (Tobien, 1973; Lucas and Morgan, 2008).

\subsection{Biochronology of Cuvieronius}

Despite references to the contrary (e.g., Kurtén and Anderson, 1980; Webb and Dudley, 1995), there is no credible evidence for the occurrence of Cuvieronius in North America prior to the beginning of the Irvingtonian (about 1.6 Ma). Among specimens that possess the symphyseal region of the lower jaws revealing the presence or absence of lower tusks, Rhynchotherium occurs only in late Hemphillian and Blancan faunas, becoming extinct in the latest Blancan at about 2.2 Ma (Lucas and Morgan, 2008), whereas Cuvieronius is restricted to early Irvingtonian and younger faunas, becoming extinct at the end of the Rancholabrean with the remainder of the Pleistocene megafauna. Specimens previously referred to Cuvieronius from Blancan faunas consist of isolated teeth or mandibles that lack the symphysis, and thus their identification cannot be confirmed. The non-overlapping biochronologic ranges of Rhynchotherium and Cuvieronius suggest an ancestor-descendant relationship between the two genera. Cuvieronius apparently evolved from Rhynchotherium in the late Blancan, with the anterior shortening of the mandibles and loss of the lower tusks. There is currently no evidence for this evolutionary transition in late Blancan faunas from temperate North America. All late Blancan specimens of this lineage that preserve the symphysis are referable to Rhynchotherium. Although Webb and Dudley (1995, p. 648) mentioned that "An early plesiomorphous (or transitional) form of Cuvieronius occurs in 
the late Blancan of Florida, e.g., at Macasphalt Pit in Sarasota Co., Florida..." an examination of the mandibles from the late Blancan Macasphalt Shell Pit, upon which their observation was based, confirms the identification of this specimen as Rhynchotherium not Cuvieronius. The lack of evidence for Cuvieronius in temperate North American Blancan faunas suggests that the evolution of this genus may have occurred in Mesoamerica where late Blancan faunas are scarce (Mexico) or absent (Central America). During the early Pleistocene, Cuvieronius dispersed across the Panamanian Isthmus and entered South America as a participant in the GABI (Lucas, 2013).

Cuvieronius occurs in early through late Pleistocene faunas (Irvingtonian and Rancholabrean NALMAs) in North America, including Central America, and early through late Pleistocene faunas (Ensenadan and Lujanian South American land mammal ages-SALMAs) in South America. The oldest confirmed specimens of Cuvieronius hyodon are early Pleistocene (early Irvingtonian, 1.6-1.0 Ma) records from North America, including the Leisey Shell Pit and Punta Gorda faunas from Florida (Webb and Dudley, 1995; Lucas, 2008a), the Tortugas Mountain fauna from New Mexico (Lucas et al., 1999; Morgan and Lucas, 2003), and the Barranco del Sisimico and Río Tomayate faunas from El Salvador (Webb and Perrigo, 1984; Cisneros, 2005). Other Irvingtonian records of Cuvieronius from New Mexico, Texas, Florida, and North Carolina consist of less diagnostic fossils that probably are not identifiable to the species level (Hibbard and Dalquest, 1966; Morgan and Hulbert, 1995; Sanders, 2002; Morgan and Lucas, 2003). Records of Cuvieronius from late Pleistocene (Rancholabrean) sites in temperate North America are not as widespread as in the Irvingtonian, with the most complete Rancholabrean specimens from Daytona Beach on the Atlantic Coast of Florida (Morgan and Hulbert, 1995) and Sinton and Ingleside on the Gulf Coast of southern Texas (Hay, 1926; 
Lundelius, 1972). Most records of Cuvieronius from Central America and Mexico appear to be late Pleistocene, although the age of many Mesoamerican proboscidean sites is problematic (Arroyo-Cabrales et al., 2007; Lucas and Alvarado, 2010).

The earliest well-dated specimens of Cuvieronius hyodon in South America are from Tarija, Bolivia (Ferretti, 2008; Mothé et al., 2013). Recent studies of the geochronology and biostratigraphy of the Tarija Fauna confirm an range age of 0.99 to $0.76 \mathrm{Ma}$, corresponding to a late early to middle Pleistocene age and referral to the Ensenadan SALMA (MacFadden, 2013; MacFadden et al., 2013).

\subsection{Biogeography of Cuvieronius}

Cuvieronius is the most common proboscidean in late Pleistocene deposits in tropical regions of North America, including southern Mexico and Central America from Guatemala south to Panama (Arroyo-Cabrales et al., 2007; Lucas and Alvarado, 2010). Cuvieronius also is known from two early Pleistocene faunas in Mesoamerica, Barranca del Sisimico and Río Tomayate in El Salvador (Webb and Perrigo, 1984; Cisneros, 2005). Cuvieronius is uncommon in the temperate portion of North America, with a rather restricted geographic distribution in the southern United States and northern Mexico. The northernmost occurrences of Cuvieronius in the Irvingtonian are from New Mexico, Texas, Florida, and North Carolina (Webb and Dudley, 1995; Lucas et al., 1999, 2000; Sanders, 2002; Lucas, 2008a). Records of Cuvieronius from two early Irvingtonian faunas from the Rio Grande valley in southern New Mexico at about 1,200 m are among the highest elevation records of this genus in North America (Lucas et al., 1999, 2000). Cuvieronius disappears from the American Southwest in the early Irvingtonian about a 
million years ago (Lucas et al., 1999), presumably related to the increasingly cooler and drier climate. The northern distribution of Cuvieronius during the Rancholabrean was restricted to the Gulf and Atlantic coastal plains of the southeastern United States, with records from Texas, Florida, and South Carolina (Hay, 1926; Lundelius, 1972; Sanders, 2002; Baskin and Thomas, 2007; Lucas, 2008a).

General patterns of Pleistocene proboscidean abundance and distribution in tropical North America reveal some interesting trends. Among the three genera of late Pleistocene proboscideans known from Mexico and Central America (Cuvieronius, Mammut, and Mammuthus), the mastodon Mammut is the rarest with 15 records from northern and central Mexico and a single record from Honduras (Arroyo-Cabrales et al., 2007; Lucas and Alvarado, 2010). The mammoth Mammuthus is the most abundant proboscidean in northern and central Mexico, but was uncommon in southern Mexico (Arroyo-Cabrales et al., 2007). Mammoths are even rarer in Central America where there are fewer than ten records, with the southernmost occurrence in northwestern Costa Rica (Lucas et al., 1997; Lucas and Alvarado, 2010). Cuvieronius was rare in the northern half of Mexico, but was the most common proboscidean in late Pleistocene faunas in southern Mexico and Central America (Arroyo-Cabrales et al., 2007; Lucas and Alvarado, 2010). In southern Central America south of $10^{\circ}$ North latitude, including central and eastern Costa Rica and Panama, Cuvieronius is the only known Pleistocene proboscidean (Gazin, 1957; Pearson, 2005; Lucas and Alvarado, 2010; Lucas, 2014).

Overall abundance patterns in North America during the late Pleistocene reveal that Mammut is the most common proboscidean in the more heavily forested eastern half of the continent, Mammuthus is most abundant in the western grasslands, and Cuvieronius is the dominant proboscidean of the savannas and tropical forests of southern Mexico and Central 
America. Mesoamerican records of Cuvieronius are found in both lowland and upland sites, but are more common in the lowlands, including the specimens reported here from the Panamanian continental shelf in the vicinity of the Pearl Islands. Despite their differing biogeographic patterns, these three genera do not have mutually exclusive distributions. Mammut and Mammuthus are found together in many late Pleistocene sites in temperate North America and Cuvieronius and Mammuthus are often associated in sites in the southern United States and Mexico. Arroyo-Cabrales et al. (2007) stated that Cuvieronius and Mammut have an ecologically parapatric distribution in Mexico. Although a rare association, Cuvieronius and Mammut are known to co-occur in several Rancholabrean sites in temperate North America, including Daytona Beach in Florida where these two genera are found with Mammuthus (Morgan and Hulbert, 1995). Cuvieronius, Mammut, and Mammuthus are also associated in the Rancholabrean Ingleside and Nueces River faunas on the Gulf Coastal Plain of southern Texas (Lundelius, 1972; Baskin and Thomas, 2007).

North American proboscidean distributional patterns were somewhat different during the early Pleistocene. Cuvieronius is more common than Mammut in Florida early Irvingtonian faunas, where Cuvieronius often occurs in association with Mammuthus, including Leisey Shell Pit and Punta Gorda (Morgan and Hulbert, 1995; Webb and Dudley, 1995). Rancholabrean records of Mammut in the southeastern United States far outnumber Cuvieronius, perhaps suggesting a change to more temperate forests after the Irvingtonian. The abundance and distribution of proboscideans in Mesoamerica during the Irvingtonian is poorly known because of the paucity of faunas of this age, although the largest reported sample of Cuvieronius from North America occurs in the early Irvingtonian Río Tomayate LF in El Salvador, a fauna that lacks other taxa of proboscideans (Cisneros, 2005). 
Among the three families of proboscideans known from the Pleistocene of North America (Elephantidae, Gomphotheriidae, Mammutidae), only the Gomphotheriidae occurs in South America. There have been numerous studies of the taxonomy, biogeography, and paleoecology of South American gomphotheres over the past decade (e.g., Sánchez-Chillón et al., 2004; Prado et al., 2005; Ferretti, 2008; Mothé et al. 2012, 2013; Lucas, 2013; Mothé and Avilla, 2015). The taxonomy of Pleistocene gomphotheres in South America is complicated because as many as four genera have been recognized, including Cuvieronius. Several recent taxonomic reviews of South American Pleistocene gomphotheres have reduced the number of valid species to two (Mothé et al. 2012, 2013; Lucas, 2013), Cuvieronius hyodon and Notiomastodon platensis. Notiomastodon can be separated from Cuvieronius by “...the absence of spiraled torsion and spiral enamel band in upper tusks... and molar teeth more complex and with larger number of cones" (Mothé et al., 2012, p. 6). South American gomphotheres previously referred to the genera Haplomastodon and Stegomastodon are included under Notiomastodon, following Mothé et al. (2012, 2013) and Lucas (2013). Haplomastodon is a synonym of Notiomastodon, whereas Stegomastodon is restricted to Blancan and early Irvingtonian faunas from North America (Morgan and Lucas, 2011; Lucas, 2013; Mothé and Avilla, 2015).

With the exception of a few records from Ecuador and Peru, the Pleistocene distribution of Cuvieronius and Notiomastodon in South America is non-overlapping. Cuvieronius is mostly restricted to upland sites in the Andes of western South America, including Ecuador, Peru, and Bolivia, although this genus is known from a few lowland localities in Ecuador (Mothé and Avilla, 2015). The adaptation of Cuvieronius to the South American uplands is supported not only by its geographic distribution, but also by isotopic studies (Sanchez-Chillón, et al 2004; 
Mothé et al., 2013). Notiomastodon is found primarily in lowland sites, but does occur in several Andean localities in Colombia, Ecuador, and Peru (Mothé and Avilla, 2015). Notiomastodon is widely distributed throughout much of South America where Cuvieronius has not been found, including Chile, Argentina, Uruguay, Paraguay, Brazil, Colombia, and Venezuela.

Notiomastodon is not known from Surinam and the Guyanas, and there are very few records from the northern Amazon basin (Mothé and Avilla, 2015).

The paleoecology of Cuvieronius in North America and South America appears to be somewhat contradictory. Cuvieronius in South America is primarily restricted to the highlands in the Andean region, with a few lowland records from Ecuador and Peru (Mothé and Avilla, 2015). In contrast, Cuvieronius in Central America is found primarily in lowland sites, including the specimens from the Pearl Islands that were collected on the continental shelf below modern sea level. Late Pleistocene proboscideans from similar lowland tropical faunas in northern South America are mostly Notiomastodon, including several localities in northwestern Colombia less than 400 km southeast of the Pearl Islands (Mothé et al., 2013; Mothé and Avilla, 2015). The closest site in South America where Cuvieronius has been identified is in northern Ecuador, about 1,000 km south of the Pearl Islands (Mothé and Avilla, 2015). There do not appear to be any obvious geographic barriers between Panama and Colombia in the late Pleistocene that would have limited the dispersal of Cuvieronius south from Central America into northern South America or Notiomastodon north from Colombia and Venezuela into Panama. During low sea level stands of the Pleistocene, narrow coastal corridors would appear to have functioned as natural dispersal routes along the Pacific coast between Panama and Colombia and the Caribbean coast between Panama and Colombia and Venezuela. 
The apparent discrepancy between the biogeography and paleoecology of Cuvieronius in North America compared South America may result from the difficulty in identifying isolated teeth of gomphotheres. A gomphothere m3 from the Pearl Islands is similar to the North American Pliocene and early Pleistocene (Blancan and early Irvingtonian) genus Stegomastodon, based on the presence of 51/2 lophs/lophids, incipient double trefoiling, and numerous accessory cusps. The early Blancan species $S$. primitivus has similar dental characters to the Pearl Islands gomphothere m3, whereas the late Blancan and early Irvingtonian species S. mirificus has $61 / 2$ or more lophs/lophids on the M3/m3, double trefoiling, and highly complicated enamel (Morgan and Lucas, 2011). Despite the general dental similarities, it is unlikely that the Pearl Islands m3 represents Stegomastodon because there is no evidence of Blancan and early Irvingtonian vertebrate faunas in Panama. Moreover, the Pliocene and early Pleistocene was a period of generally high worldwide sea levels, whereas the teeth from the Pearl Islands must date to a glacial interval based on their occurrence on the continental shelf below modern sea level.

Prior to recent taxonomic revisions (Mothé et al., 2012; Lucas 2013), South American gomphotheres now referred to Notiomastodon platensis were often placed in the genus Stegomastodon. This identification was based on the overall similarity between Notiomastodon (including Haplomastodon) and Stegomastodon, including complicated teeth, absence of lower tusks, and gently curved to nearly straight upper tusks lacking torsion and an enamel band. Most proboscidean workers now consider Stegomastodon to be a strictly North American genus, and regard its similarity to Notiomastodon as an example of morphological convergence (Mothé et al., 2012; Lucas, 2013). However, the general similarity of Notiomastodon to Stegomastodon, and the superficial resemblance of at least one of the gomphothere teeth from the Pearl Islands to 
Stegomastodon, leads to the suggestion that both Cuvieronius and Notiomastodon might be present in the sample of gomphothere teeth from the Pearl Islands.

Detailed comparisons of gomphothere specimens from Central America with Notiomastodon from northern South America and Cuvieronius from southern South America, as well as the discovery of more diagnostic specimens in Central America, preferably including jaws and skulls, will be required before the identification of tropical American gomphotheres can be fully resolved. For purposes of the present study, we follow current taxonomic doctrine and recognize the gomphothere teeth from the Pearl Islands as Cuvieronius hyodon, with the caveat that further study may require a name change at least one of the specimens.

\subsection{Proboscidean fossils from the continental shelf}

The discovery of four gomphothere teeth from the continental shelf in the Gulf of Panama has prompted a more comprehensive review of Quaternary fossils of large terrestrial mammals from the continental shelf. Quaternary proboscidean teeth are well known from the continental shelf off the Atlantic Coast of the northeastern United States (Whitmore et al., 1967) and in the North Sea (van Kolfschoten and Laban, 1995; Mol et al., 2006), but are not well documented from tropical regions. Whitmore et al. (1967) recorded teeth of mammoths (Mammuthus) or mastodons (Mammut) from more than 40 sites at depths of 20-120 m along the continental shelf of the western North Atlantic Ocean, from the latitude of Massachusetts south to North Carolina. Large numbers of Pleistocene fossils representing a wide variety of terrestrial mammals have been dredged by fisherman from the Southern Bight of the North Sea between England and the Netherlands (van Kolfschoten and Laban, 1995; Mol et al., 2006). Among the 
most abundant of the North Sea Pleistocene fossils are isolated teeth of the woolly mammoth Mammuthus primigenius. Other reports of proboscidean teeth from the continental shelf include records from Japan, southern California, and Brazil (Whitmore et al., 1967; Lopes and Buchmann, 2011).

Several factors help to explain the abundance of proboscidean teeth in fossil samples dredged from the continental shelf by fisherman. Proboscidean teeth are large and sturdy, so would be more likely to have survived on the sea floor for more than 10,000 years. Teeth of the American mastodon (Mammut americanum) are more common on the northeastern U. S. continental shelf than are mammoth teeth (Mammuthus columbi and M. primigenius), at least in part because mastodon teeth are stronger, being composed of a continuous layer of thick enamel. Mammoth teeth consist of plates of dentine surrounded by rather thin enamel and held together by softer cement, causing the teeth to break apart between the plates (Whitmore et al., 1967). The teeth of Cuvieronius are similar to teeth of Mammut, with a continuous layer of thick enamel. Whitmore et al. (1967) mentioned only a few other species of large Pleistocene mammals caught in nets by fisherman off the northeastern coast of the United States, including the woodland musk ox Bootherium and the large cervid Cervalces. A diverse sample of large Pleistocene mammals, the so-called "Mammoth Fauna," is known from the shallow waters of the North Sea, including woolly mammoth, woolly rhino, horse, Irish elk, muskox, bison, cave bear, and cave lion, among others (van Kolfschoten and Laban, 1995; Mol et al., 2006).

There are several examples of Quaternary vertebrate fossils found on the continental shelf in subtropical regions closer to Panama. Fossils of Mammut americanum, giant ground sloth Eremotherium laurillardi, Bison, and giant land tortoise Hesperotestudo crassiscutata have been caught in shrimp nets at depths of about $10 \mathrm{~m}$ in Nassau Sound, a small embayment of the 
Atlantic Ocean at the mouth of the Nassau River in northeastern Florida at about $30^{\circ}$ North latitude (FLMNH vertebrate paleontology collection). Almost all of these fossils have attached specimens of modern marine invertebrates. Fossils of the pampathere Holmesina, the cheetahlike cat Miracinonyx, the horse Equus, and a proboscidean were collected by a scuba diver from a depth of about $20 \mathrm{~m}$ in the Gulf of Mexico about $25 \mathrm{~km}$ west of St. Petersburg, Florida at about $28^{\circ}$ North latitude (Morgan and Seymour, 1997; FLMNH vertebrate paleontology collection). Several of these specimens also had attached marine invertebrates, including coral. Tunnell (1991) reported a mammoth tooth collected by a commercial shrimp trawler from a depth of 55 $\mathrm{m}$ on the continental shelf off Port Isabel along the Gulf Coast of Texas at about $26^{\circ}$ North latitude.

Fossils of large Pleistocene mammals have been caught by fisherman in bottom trawlers from depths between 20 and $50 \mathrm{~m}$ on the Atlantic continental shelf about 20-40 km offshore from the State of Rio Grande do Sul in southern Brazil, between $31^{\circ}$ and $33^{\circ}$ South latitude (Lopes and Buchmann, 2011). The Brazilian fossils include the tooth of a gomphothere and a partial skull, humerus, and femur of the toxodont Toxodon, all of which had attached specimens of modern marine invertebrates. The gomphothere tooth, a lower m3 of Notiomastodon platensis (referred to Stegomastodon waringi by Lopes and Buchmann, 2011, but see taxonomic discussion above), is of particular interest because of its similarity to the occurrence of the gomphothere teeth from the Pearl Islands. This tooth has 51/2 lophids that are angled from anterior to posterior and complicated enamel (Lopes and Buchmann, 2011), and bears a strong resemblance to a lower m3 (STRI/CTPA 1) from the Pearl Islands here referred to Cuvieronius hyodon. We are not aware of any published records of terrestrial vertebrate fossils from the 
continental shelf along the Pacific Coast between southern California and the Pearl Islands or in the Gulf of Mexico or the Caribbean Sea south of Florida and Texas.

\section{Conclusions}

Four proboscidean teeth from the continental shelf near the Pearl Islands in the Gulf of Panama, about 50 to $80 \mathrm{~km}$ offshore from the southern coast of Panama, are identified as the Pleistocene gomphothere Cuvieronius hyodon. Three complete third molars from the Pearl Islands, two M3s and one m3, exhibit a range of dental morphology: from $4 \frac{1}{2}$ to $5 \frac{1}{2}$ lophs/lophids that are either horizontal or set at an angle to the long axis of the tooth and rather simple enamel with single trefoils and limited development of small accessory cusps to more complex enamel with incipient double trefoils and numerous accessory cusps. Despite a rather significant range of dental variation, teeth of Cuvieronius from the southern United States, Mexico, and Central America, as well as the Pearl Islands, are referred to the pan-American species $C$. hyodon, which is also known from the Andean region of South America.

Cuvieronius can be differentiated from the closely related by Rhynchotherium by the shortened mandibular symphysis, lack of lower tusks, and more complicated enamel on the cheek teeth, particularly the M3s/m3s. Cuvieronius and Rhynchotherium are closely related based on the shared-derived character of spiraled upper tusks. The biochronology of these two genera in North America suggests an ancestor-descendant relationship: Rhynchotherium is known only from late Hemphillian and Blancan faunas; Cuvieronius is restricted to Irvingtonian and Rancholabrean faunas. The absence of Cuvieronius in temperate North American late Blancan faunas suggests this genus may have evolved from Rhynchotherium in Central America. 
Cuvieronius reached South America in the early Pleistocene where it is first recorded from the Tarija fauna in Bolivia. Cuvieronius is the only Pleistocene gomphothere in Central America. In South America, this genus is primarily restricted to highland sites in Ecuador, Peru, and Bolivia. Notiomastodon is the common gomphothere in lowland Pleistocene faunas in South America, including sites in Colombia and Venezuela that are within $400 \mathrm{~km}$ of the Pearl Islands.

Similarities between teeth of Notiomastodon and at least one of the gomphothere teeth from the Pearl Islands, and the lack of geographic barriers between Panama and northern South America during the late Pleistocene, suggest that the taxonomy of lowland gomphotheres in the northern Neotropics needs further study.

Two teeth of Cuvieronius hyodon from the Pearl Islands were recovered in nets by shrimp fisherman from depths of about $90 \mathrm{~m}$, indicating that these fossils date to the Last Glacial Maximum between 30 and $15 \mathrm{ka}$, when sea level was as much as $120 \mathrm{~m}$ lower than present and the Gulf of Panama was dry land. Large areas of the continental shelf worldwide were subaerially exposed for significant periods of time since continental glaciation commenced at the beginning of the Pleistocene about 2.6 Ma, and should provide an excellent source of Pleistocene fossils of proboscideans and other large land mammals. Nonetheless, Pleistocene fossils from the continental shelf are only rarely reported, and are particularly uncommon from tropical regions such as Panama. Only in the North Sea between the Netherlands and England (van Kolfschoten and Laban, 1995; Mol et al., 2006), and to a lesser extent the western North Atlantic off the northeastern coast of the United States (Whitmore et al., 1967), has there been a systematic attempt to document the Pleistocene mammal fauna recovered from the continental shelf. Elsewhere, information on late Pleistocene vertebrate fossils from the continental shelf has been obtained primarily from fishermen who occasionally notify paleontologists at museums or 
universities about fossils recovered from their nets. Interviewing fisherman in Panama who net shrimp or fish in the shallow waters of the Gulf of Panama would probably reveal the existence of more Quaternary fossils than the four gomphothere teeth reported here.

\section{Acknowledgments}

David Bohaska assisted in our research on specimens in the U. S. National Museum of Natural History (USNM) from El Hatillo, Panama collected by Lewis Gazin. Dimila Mothé from the Laboratório de Mastozoologia (UNIRIO) in Rio de Janeiro, Brazil and Marco Ferretti, University of Firenze, Italy, provided helpful information on South American gomphotheres. Richard Cooke, Carlos Jaramillo, George Angehr, and Aaron Wood helped with our studies of a gomphothere tooth in the collection of STRI/CTPA. This study is part of the PCP (Panama Canal Project) PIRE (Partnerships in International Research and Education) project and was supported by US National Science Foundation grant 0966884 (OISE, EAR, DRL).

\section{References}

Arroyo-Cabrales, J., Polaco, O. J., Laurito, C., Johnson, E., Alberdi, M. T., Valerio Zamora, A. L., 2007. The proboscideans (Mammalia) from Mesoamerica. Quaternary International $169-170,17-23$.

Baskin, J. A., Thomas, R. G., 2007. South Texas and the Great American Interchange. Gulf Coast Association of Geological Societies Transactions 57, 37-45. 
Bell, C. J., Lundelius, E. L., Jr., Barnosky, A. D., Graham, R. W., Lindsay, E. H., Ruez, D. R., Jr., Semken, H. A., Jr., Webb, S. D., Zakrzewski, R. J., 2004. The Blancan, Irvingtonian, and Rancholabrean mammal ages. In: Woodburne, M. O. (Ed.), Late Cretaceous and Cenozoic mammals of North America: Biostratigraphy and geochronology. Columbia University Press, New York, pp. 232-314.

Boule, M., Thevenin, A., 1920. Mammifères fossiles de Tarija, First ed. Imprimerie nationale, Mission Scientifique, G. de Créqui-Monfort et F. Sénéchal de la Grange, Paris. 256 p.

Cartelle, C., de Iuliis. G., 1995. Eremotherium laurillardi: the Panamerican Late Pleistocene megatheriid sloth. Journal of Vertebrate Paleontology 15, 830-841.

Cione, A. L., Tonni, E. P., 1995. Chronostratigraphy and "Land Mammal Ages" in the Cenozoic of southern South America: principles, practices, and the "Uquian" problem. Journal of Paleontology 69, 135-159.

Cisneros, J. C., 2005. New Pleistocene vertebrate fauna from El Salvador. Revista Brasileira de Paleontologia 8, 239-255.

Cope, E. D., 1884. The extinct Mammalia of the Valley of Mexico. Proceedings of the American Philosophical Society, 22 (117), 1-21.

Cope, E. D., 1893. A preliminary report on the vertebrate paleontology of the Llano Estacado. Texas Geological Survey, $4^{\text {th }}$ Annual Report, 136 p.

Ferretti, M. P., 2008. A review of South American proboscideans. New Mexico Museum of Natural History and Science Bulletin 44, 381-391.

Fischer de Waldheim, G., 1814. Zoognosia, Tabulis synopticis illustrat, vol. 3, 694 p.

Gazin, C. L., 1957. Exploration for the remains of giant ground sloths in Panama. Smithsonian Institution Annual Report 1956, 341-354. 
Gibbard, P. L., Head, M. J., Walker, M J. C. and the Subcommission on Quaternary Stratigraphy, 2010. Formal ratification of the Quaternary system/period and the Pleistocene series/epoch with a base at 2.58 Ma. Journal of Quaternary Science 25, 96-102.

Hay, O. P., 1926. A collection of Pleistocene vertebrates from southwestern Texas. Proceedings of the United States National Museum, 68 (24), 1-18.

Hibbard, C. W., Dalquest, W. W., 1966. Fossils from the Seymour Formation of Knox and Baylor counties, Texas, and their bearing on the late Kansan climate of that region. Contributions from the Museum of Paleontology, University of Michigan 21(1), 1-66.

Kolfschoten, T. van, Laban, C., 1995. Pleistocene terrestrial mammal faunas from the North Sea. Mededelingen Rijks Geologische Dienst 52, 135-151.

Kurtén, B., Anderson, E., 1980. The Pleistocene mammals of North America. Columbia University Press, New York.

Lambeck, K., Esat, T. M., Potter, E. K., 2002. Links between climate and sea levels for the past three million years. Nature 419, 199-206.

Lambert, W. D., 2007. New tetralophodont gomphothere material from Nebraska and its implications for the status of North American Tetralophodon. Journal of Vertebrate Paleontology 27, 676-682.

Lambert, W. D., Shoshani, J., 1998. Proboscidea. In: Janis, C. M., Scott, K. M., Jacobs, L. L. (Eds.), Evolution of Tertiary mammals of North America. Volume 1: terrestrial carnivores, ungulates, and ungulatelike mammals. Cambridge University Press, Cambridge, pp. 606-621.

Lopes, R. P., Buchmann, F. S., 2011. Pleistocene mammals from the southern Brazilian continental shelf. Journal of South American Earth Sciences 31, 17-27. 
Lucas, S. G., 2008a. Cuvieronius (Mammalia, Proboscidea) from the Neogene of Florida. New Mexico Museum of Natural History and Science Bulletin 44, 31-38.

Lucas, S. G., 2008b. Late Cenozoic fossil mammals from the Chapala rift basin, Jalisco, Mexico. New Mexico Museum of Natural History and Science Bulletin 44, 39-49.

Lucas, S. G., 2013. The palaeobiogeography of South American gomphotheres. Journal of Palaeogeography 2, 19-40.

Lucas, S. G., 2014. Late Pleistocene mammals from El Hatillo, Panama. Revista Geológica de América Central 50, 139-151.

Lucas, S. G., Alvarado, G. E., 2010. Fossil Proboscidea from the upper Cenozoic of Central America: taxonomy, evolutionary and paleobiogeographic significance. Revista Geológica de América Central 42, 9-42.

Lucas, S. G., Alvarado, G. E., Vega, E., 1997. The Pleistocene mammals of Costa Rica. Journal of Vertebrate Paleontology 17, 413-427.

Lucas, S. G., Morgan, G. S., 2008. Taxonomy of Rhynchotherium (Mammalia, Proboscidea) from the Miocene-Pliocene of North America. New Mexico Museum of Natural History and Science Bulletin 44, 71-87.

Lucas, S. G., Morgan, G. S., Estep, J. W., 2000. Biochronological significance of the cooccurrence of the proboscideans Cuvieronius, Stegomastodon, and Mammuthus in the lower Pleistocene of southern New Mexico. New Mexico Museum of Natural History and Science Bulletin 16, 209-216.

Lucas, S. G., Morgan, G. S., Estep, J. W., Mack, G. H., Hawley, J. W., 1999. Co-occurrence of the proboscideans Cuvieronius, Stegomastodon, and Mammuthus in the lower Pleistocene of southern New Mexico. Journal of Vertebrate Paleontology19, 595-597. 
Lundelius, E. L., Jr., 1972. Fossil vertebrates from the late Pleistocene Ingleside fauna, San Patricio County, Texas. Bureau of Economic Geology, University of Texas at Austin, Report of Investigations 77, 1-74.

MacFadden, B. J., 2013. Dispersal of Pleistocene Equus (Family Equidae) into South America and calibration of GABI 3 based on evidence from Tarija, Bolivia. PLoS ONE 8(3): e59277. doi:10.1371/journal.pone.0059277.

MacFadden, B. J., Zeitler, P. K., Anaya, F., Cottle, J. M., 2013. Confirmation of the middle Pleistocene age of the sedimentary sequence from Tarija, Bolivia. Quaternary Research 79, 268-273.

Marshall, L., Berta, A., Hoffstetter, R., Pascual, R., Reig, O., Bombin, M., Mones, A., 1984. Mammals and stratigraphy: geochronology of the continental mammal-bearing Quaternary of South America. Paleovertebrata, Memoire Extraordinaire, 1-76.

Meyer, H. von, 1867. Studien ueber das genus Mastodon. Paleontographica 18, 1-72.

Mol, D., Post, K., Reumer, J. W. F., van der Plicht, J., de Vos, J., van Geel, B., van Reenen, G., Pals, J. P., Glimmerveen, J., 2006. The Eurogeul—first report of the paleontological, palynological, and archaeological investigations of this part of the North Sea. Quaternary International 142-143, 178-185.

Morgan, G. S., Hulbert, R. C., Jr., 1995. Overview of the geology and vertebrate paleontology of the Leisey Shell Pit Local Fauna, Hillsborough County, Florida. Bulletin of the Florida Museum of Natural History 37 (Part I), 1-92.

Morgan, G. S., Lucas, S. G., 2003. Mammalian biochronology of Blancan and Irvingtonian (Pliocene and early Pleistocene) faunas from New Mexico. Bulletin of the American Museum of Natural History 278, 269-320. 
Morgan, G. S., Lucas, S. G., 2011. Stegomastodon (Mammalia: Proboscidea: Gomphotheriidae) from the Blancan and Irvingtonian (Pliocene and early Pleistocene) of New Mexico. New Mexico Museum of Natural History and Science Bulletin 53, 570-582.

Morgan, G. S., Seymour, K. L., 1997. Fossil history of the panther (Puma concolor) and the cheetah-like cat (Miracinonyx inexpectatus) in Florida. Bulletin of the Florida Museum of Natural History 40, 177-219.

Mothé, D., Avilla, L. S., 2015. Mythbusting evolutionary issues on South American Gomphotheriidae (Mammalia: Proboscidea). Quaternary Science Reviews 110, 23-35.

Mothé, D., Avilla, L. S., Cozzuol, M. A., 2013.The South American gomphotheres (Mammalia, Proboscidea, Gomphotheriidae): taxonomy, phylogeny, and biogeography. Journal of Mammalian Evolution 20, 23-32.

Mothé, D., Avilla, L. S., Cozzuol, M. A., Winck, G. R., 2012. Taxonomic revision of the Quaternary gomphotheres (Mammalia: Proboscidea: Gomphotheriidae) from the South American lowlands. Quaternary International 276-277, 2-7.

Osborn, H. F., 1936. Proboscidea, Vol. I. Moertheriodea, Deinotheriodea, Mastodontoidea. The American Museum Press, New York.

Pearson, G. A., 2005. Late Pleistocene megafaunal deposits on the Isthmus of Panama and their paleoenvironmental implications. Caribbean Journal of Science 41, 1-13.

Prado J. L., Alberdi, M. T., Azanza, B., Sánchez, B., Frassinetti, D., 2005. The Pleistocene gomphotheres (Proboscidea) from South America. Quaternary International 126-128, 2130. 
Sánchez-Chillón B., Prado, J. L., Alberdi, M. T., 2004. Feeding ecology, dispersal, and extinction of South American Pleistocene gomphotheres (Gomphotheriidae, Proboscidea). Paleobiology 30, 146-161.

Sanders, A. E., 2002. Additions to the Pleistocene mammal faunas of South Carolina, North Carolina, and Georgia. Transactions of the American Philosophical Society 92 (5), 1-152.

Savage, D.E., 1955. A survey of various Late Cenozoic vertebrate faunas of the Panhandle of Texas. Part II. Proboscidea. University of California Publications in Geological Sciences $31,51-72$.

Tobien, H., 1973. On the evolution of mastodonts (Proboscidea, Mammalia), part 1: The bunodont trilophodont groups. Notizblatt des Hessischen Landesamtes fur Bodenforschung zu Wiesbaden 101, 202-276.

Tunnell, J. W., 1991. Pleistocene vertebrate fossils from the continental shelf, NW Gulf of Mexico. National Park Service Paleontology Research Abstract Volume, Technical Report NPS/NRPEFO/NRTR-93/11, p. 57.

Webb, S. D., Dudley, J. P., 1995. Proboscidea from the Leisey Shell Pits, Hillsborough County, Florida. Bulletin of the Florida Museum of Natural History 37 (Part II), 645-660.

Webb, S. D., Perrigo, S. C., 1984. Late Cenozoic vertebrates from Honduras and El Salvador. Journal of Vertebrate Paleontology 4, 237-254.

Whitmore, F. C., Jr., Emery, K. O., Cooke, H. B. S., Swift, D. J. P., 1967. Elephant teeth from the Atlantic Continental Shelf. Science 156, 1477-1481. 
Table 1. Dental measurements of third upper and lower molars (M3/m3) of Cuvieronius hyodon from the Pearl Islands, Panama, compared to measurements of teeth of $C$. hyodon from Mexico, New Mexico, Texas, and Florida. The teeth from Panama, Mexico, Texas, and Daytona Beach, Florida are Rancholabrean NALMA in age. The specimens from Leisey Shell Pit and Punta Gorda in Florida and Tortugas Mountain in New Mexico are early Irvingtonian NALMA. Museum acronyms are: MCNP (Museo de Ciencias Naturales, Panama); STRI/CTPA (Smithsonian Tropical Research Institute/Center for Tropical Paleontology and Archaeology, Panama); INAH-MRG (Instituto Nacional de Antropologia e Historia-Museo Regional de Guadalajara, Jalisco, Mexico); MPG (Museo de Paleontologia de Guadalajara, Jalisco, Mexico); NMMNH (New Mexico Museum of Natural History); NMSU (New Mexico State University, Biology Department); TMM (Texas Memorial Museum, University of Texas, Austin); UF (Florida Museum of Natural History, University of Florida); UF/DMAS (Daytona Museum of Arts and Sciences, specimens housed in the UF collection); USNM (U. S. National Museum of Natural History, Smithsonian Institution). All measurements are in $\mathrm{mm}$.

Locality and tooth position total length maximum width

Pearl Islands, Panama

USNM 421665

MCNP 1 right M3

182

84 right M3

197

84

MCNP 2

right $\mathrm{m} 2 / \mathrm{m} 3$ (partial)

STRI/CTPA 1 right $\mathrm{m} 3$

201

88

El Hatillo, Panama

USNM 540665

m3 (heavily worn)

185

92

Lago Chapala, Jalisco, Mexico ${ }^{1}$

INAH-MRG uncat. right $\mathrm{M} 3$

173

85

MPG uncat

M3

201

91

INAH-MRG uncat. right $\mathrm{m} 3$

198

82

INAH-MRG uncat. right $\mathrm{m} 3$

82

MPG 5

$\mathrm{m} 3$

199

94

MPG 712

$\mathrm{m} 3$

193

87

MPG 726

$\mathrm{m} 3$

179

82 
Locality and tooth position

total length

maximum width

Tortugas Mountain, New Mexico

NMMNH 27232

right M3

211

106

NMSU 79.17.1

right $\mathrm{m} 3$

183

83

Ingleside, Texas $^{3}$

TMM 30967-1219

right $\mathrm{m} 3$

Sinton, Texas ${ }^{4}$

USNM 11377

right $\mathrm{M} 3$

202

225

105

left $\mathrm{m} 3$

101

Leisey Shell Pit, Florida ${ }^{5}$

UF 129033

left M3

181

91

Punta Gorda, Florida ${ }^{5}$

UF 9741

right $\mathrm{M} 3$

178

87

UF 9742

left $\mathrm{m} 3$

UF 11230

right $\mathrm{m} 3$

192

85

187

87

Daytona Beach, Florida ${ }^{5}$

UF/DMAS 571

right $\mathrm{m} 3$

UF/DMAS 694

right $\mathrm{m} 3$

192

83

$194 \quad 85$

\footnotetext{
${ }^{\mathrm{T}}$ Measurements from Lucas (2008b)

${ }^{2}$ Measurements from Lucas et al. (2000)

${ }^{3}$ Measurements from Lundelius (1972)

${ }^{4}$ Measurements from Hay (1926)

${ }^{5}$ Measurements from Lucas (2008a)
} 


\section{FIGURE CAPTIONS}

Figure 1. Map of Panama showing the location of late Pleistocene sites containing the gomphothere Cuvieronius hyodon. Sites 1-2 are on the Azuero Peninsula. Site 1. La Trinidaíta.

Site 2. El Hatillo. Sites 3-5 are in the Gulf of Panama in the vicinity of the Pearl Islands. Site 3. 8 km west of Isla de Pedro González (abbreviated P. G.) and 10 km northwest of Isla de San José. Site 4. Near Isla de San José. Site 5. South of Isla del Rey. The break in slope at the bottom of the map indicates the edge of the continental slope at about $200 \mathrm{~m}$ depth.

Figure 2. Right m3 of Cuvieronius hyodon from south of Isla del Rey, Pearl Islands, Panama (STRI/CTPA 1). A. Lingual view, B. occlusal view.

Figure 3. Right M3 of Cuvieronius hyodon from Isla de San José, Pearl Islands, Panama (MCNP 1). A. Occlusal view, B. ventral view, C. enlarged view of a portion of the ventral surface showing attached specimens of modern marine invertebrates.

Figure 4. Partial right m2/m3 of Cuvieronius hyodon from Isla de San José, Pearl Islands, Panama (MCNP 2). A. Occlusal view, B. ventral view. Note attached specimens of modern marine invertebrates on ventral surface.

Figure 5. Right M3 of Cuvieronius hyodon from near Isla de San José and Isla de Pedro González, Pearl Islands (USNM 421665). A. Labial view, B. occlusal view. 


\section{Caribbean Sea}

\section{Panama}

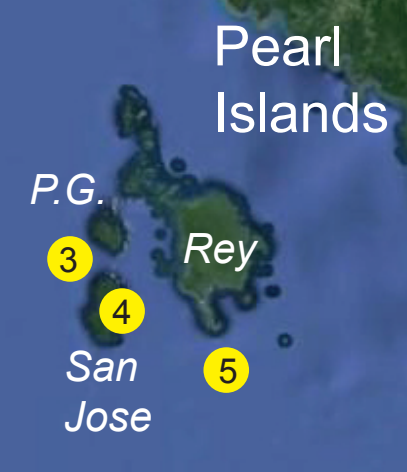

\section{Gulf of Panama}

Peninsula 
A

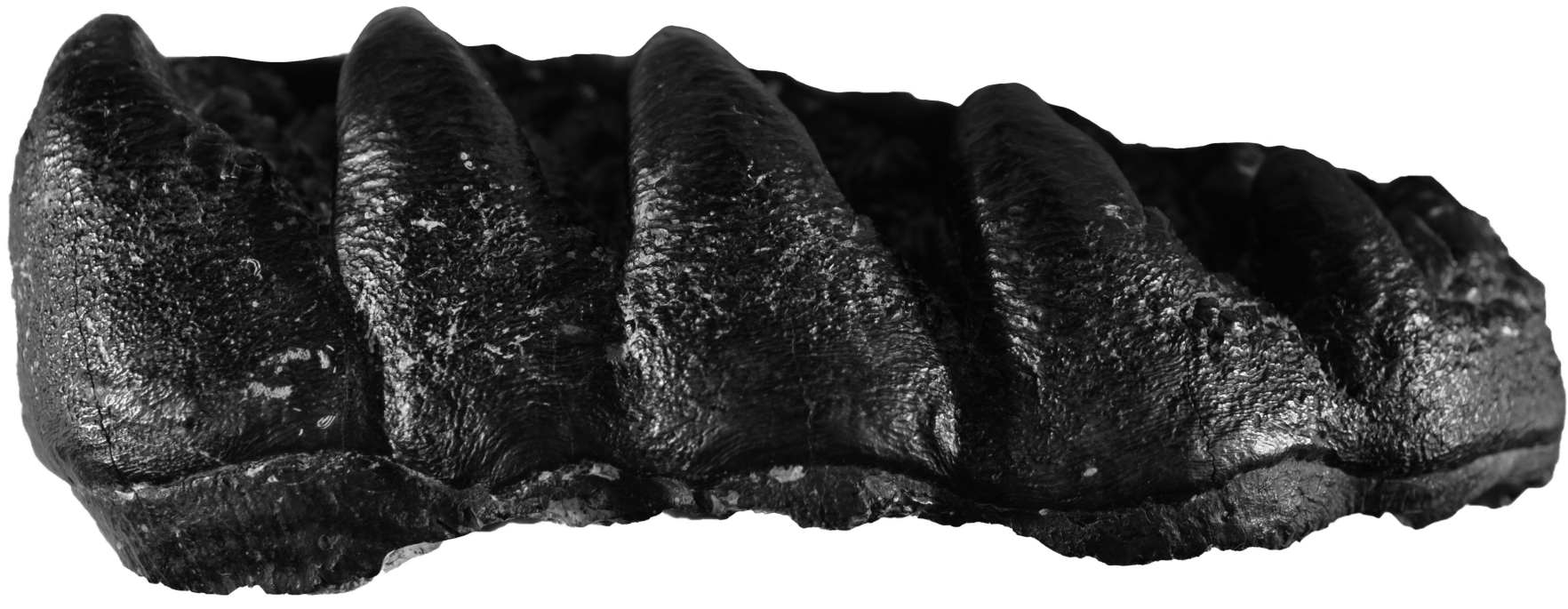

$5 \mathrm{~cm}$

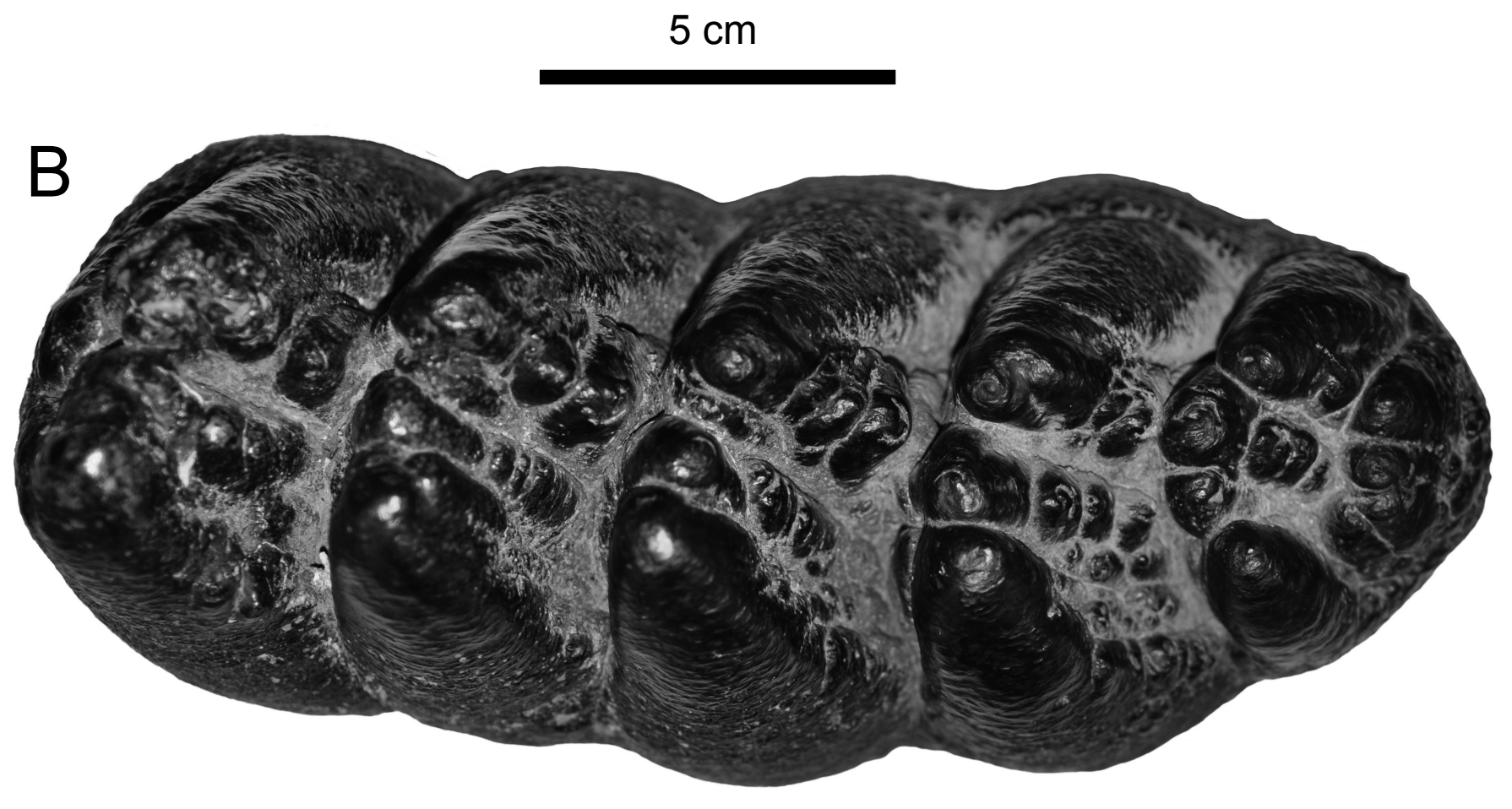

Figure 
Figure
A

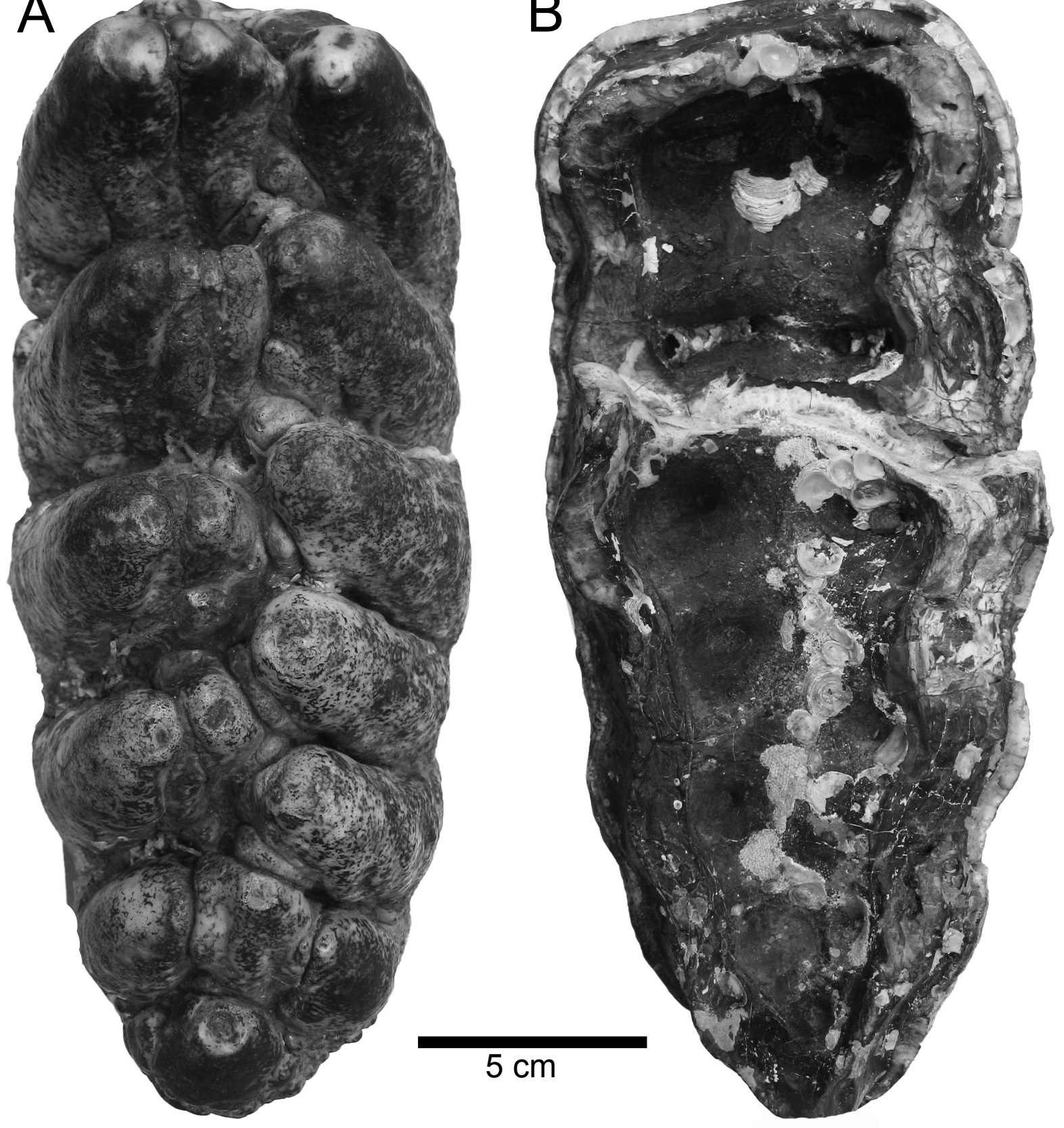

C
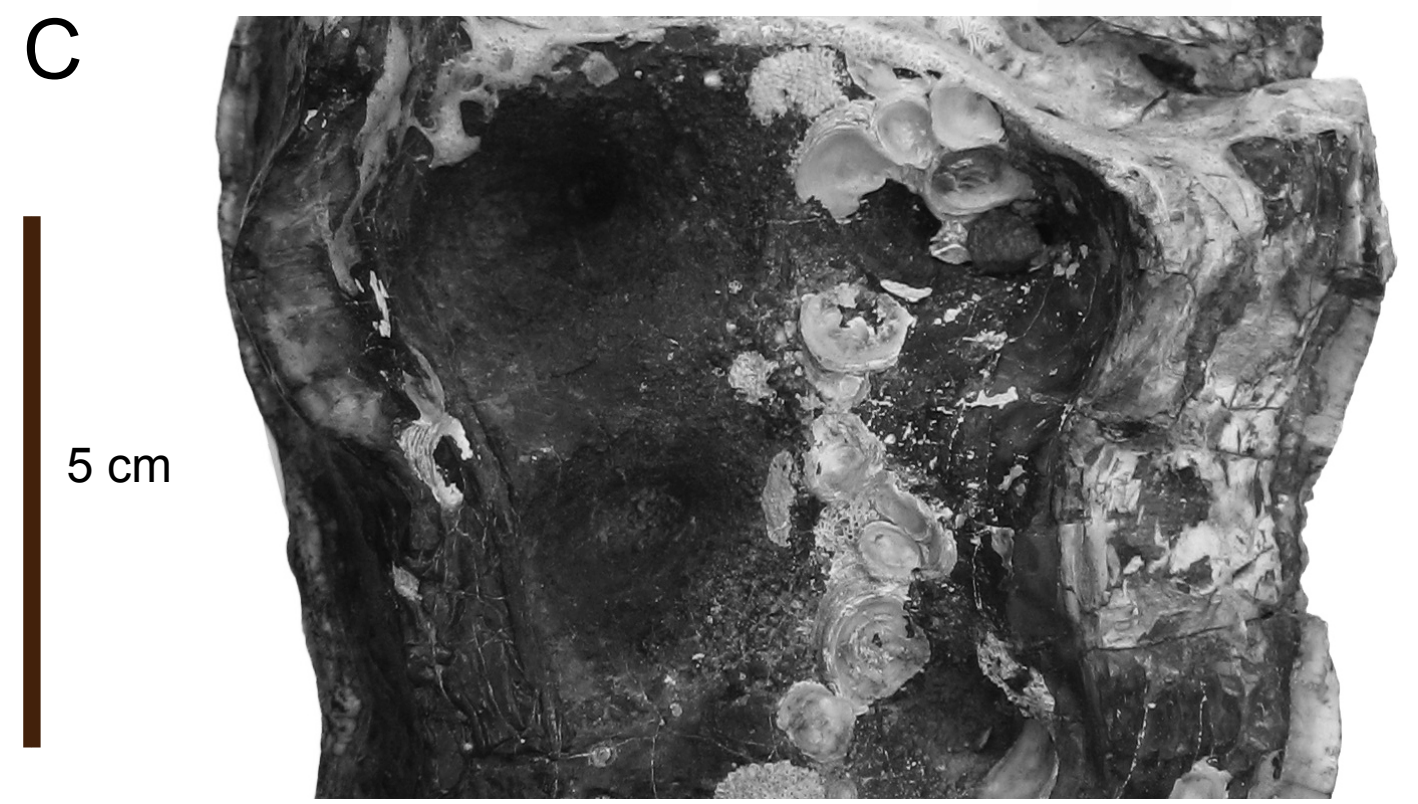


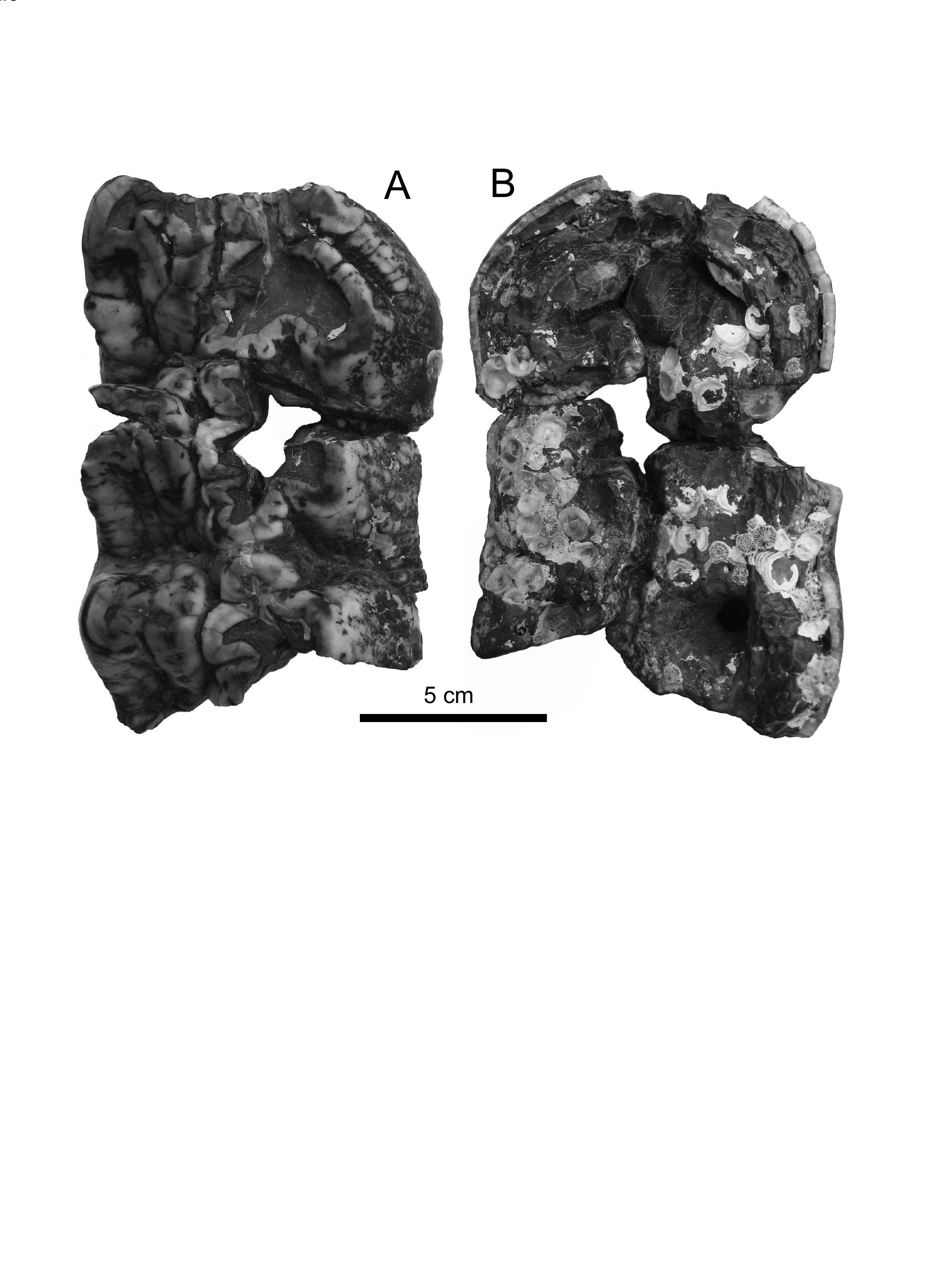

Figure

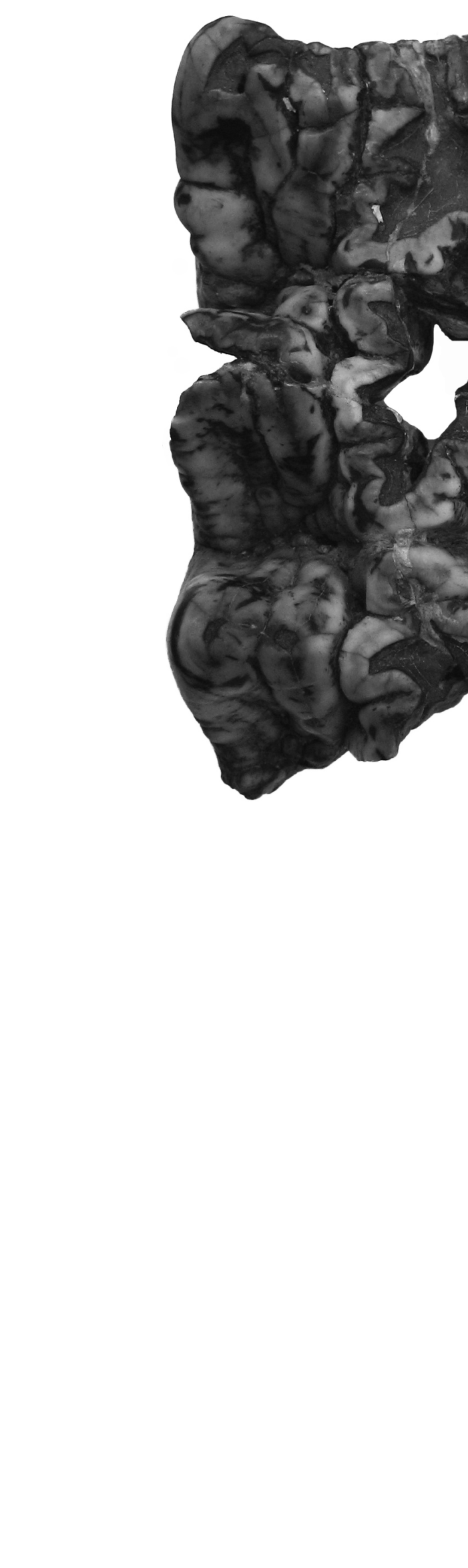

.

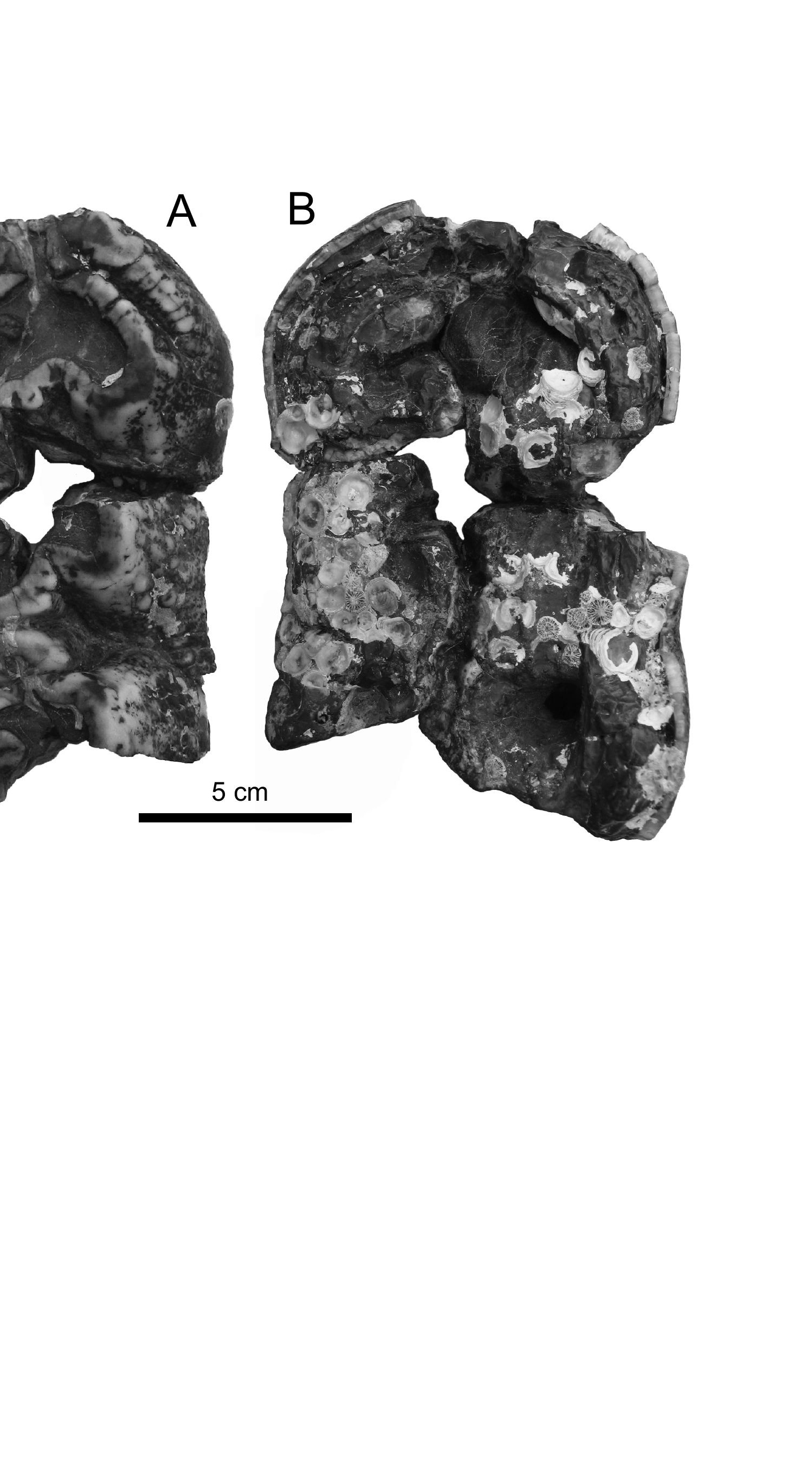



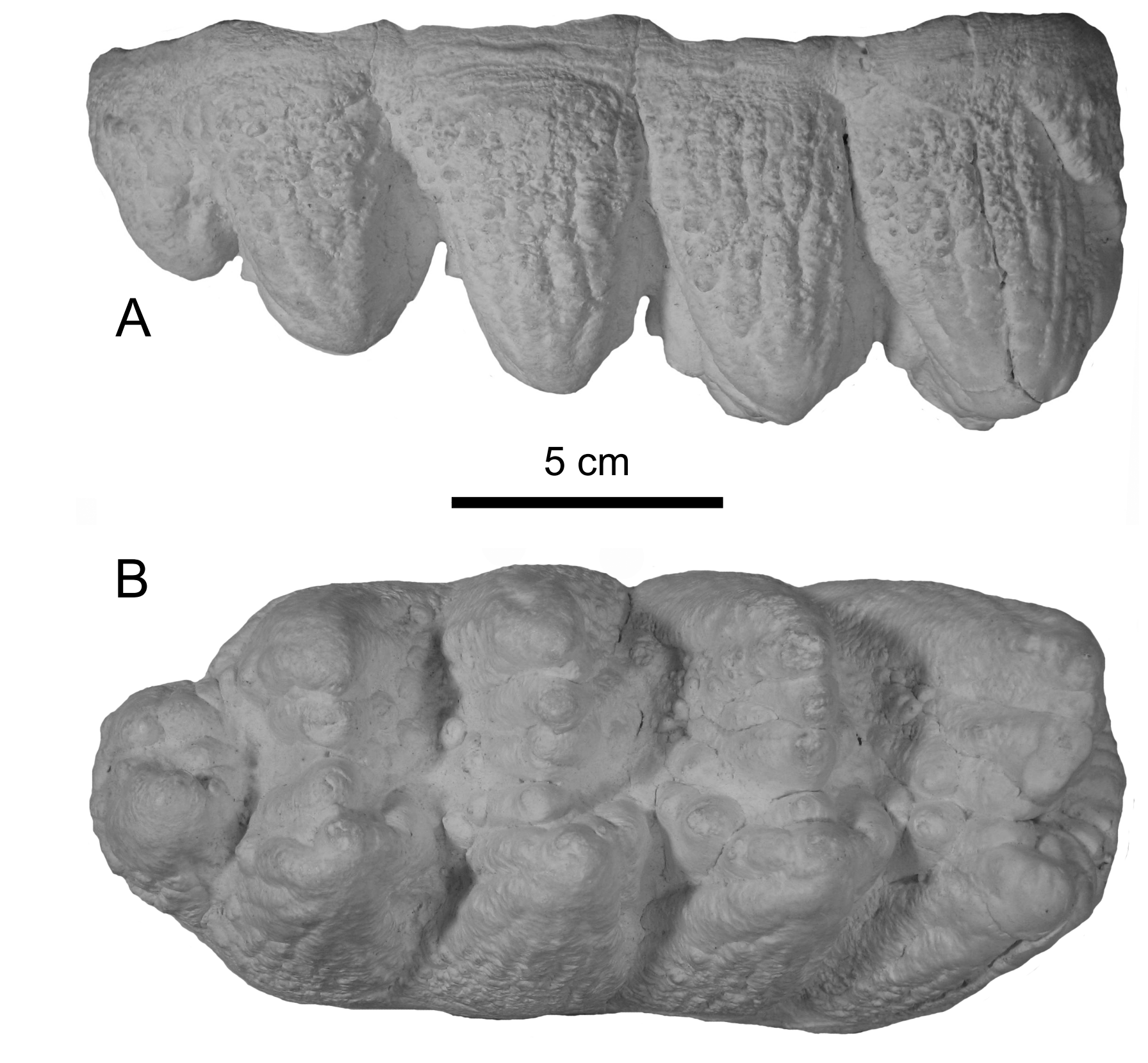

Figure

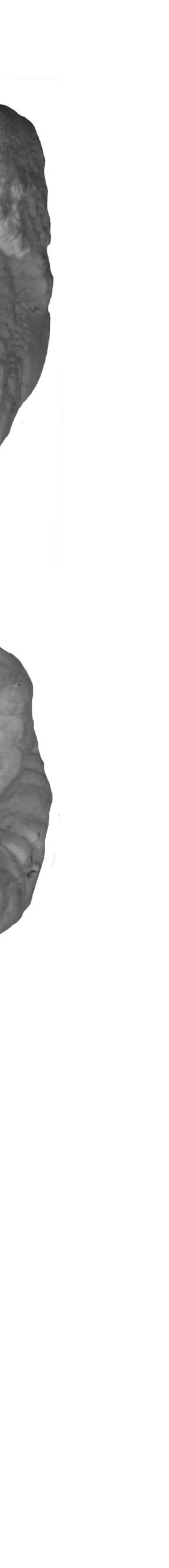

$5 \mathrm{~cm}$

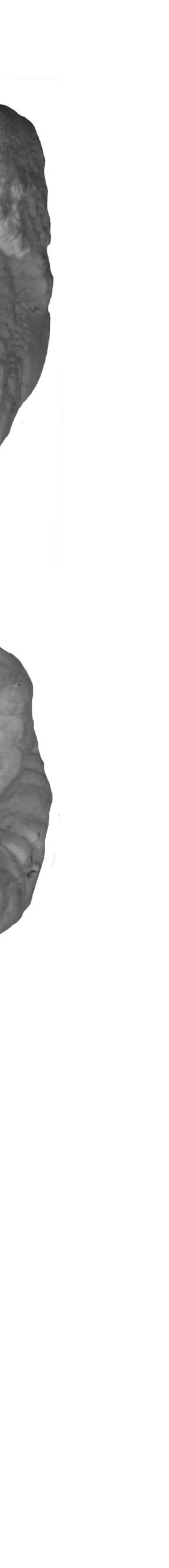




\section{Detailed response to reviewers}

Dr. Norm Catto

Editor-in-Chief

Quaternary International

Dear Dr. Catto,

I just resubmitted the revised version of my manuscript entitled "QUATERNARY

GOMPHOTHERES (MAMMALIA: PROBOSCIDEA: GOMPHOTHERIIDAE) FROM THE CONTINENTAL SHELF, PEARL ISLANDS, PANAMA" to Quaternary International.

I made almost all of the revisions suggested by the reviewers below. My comments on the reviewers suggested changes are given in red type below.

Please don't hesitate to contact me if you have any questions about my revised manuscript.

Thanks very much.

Best regards, Gary Morgan

Gary S. Morgan

Curator of Vertebrate Paleontology

New Mexico Museum of Natural History

1801 Mountain Road NW

Albuquerque, NM 87104

Phone: 505-841-2868

Email: gary.morgan1@ state.nm.us

Dear Mr. Gary S. Morgan,

Reviewers have now commented on your paper. You will see that they are advising that you revise your manuscript. If you are prepared to undertake the work required, I would be pleased to reconsider your revised manuscript.

This manuscript is very well written and brings a great overview about the Systematic and Biogeography of the gomphothere Cuvieronius hyodon. Although the specimens described in the manuscript are isolated molars, usually with little taxonomic value, the issues discussed by the authors about the variation of dental morphology, temporal range and records of this gomphothere is very clear and important to the Taxonomy and Evolution of Gomphotheriidae. The comments and modifications suggested to this manuscript are: 


\section{Page 1}

Line "America and the Andean highlands of Peru, Bolivia, and Chile in South America": Cuvieronius in South America is present in Ecuador, Peru and Bolivia, and it is absent from Chile. See Mothé \& Avilla, 2015.

I made the changes in the geographic distribution of Cuvieronius in South America.

Line "comprising the lowland tropics of northern South America was populated by the gomphothere Notiomastodon during the late Pleistocene": Notiomastodon is present from lowlands to highlands in South America, including Andean localitites in Ecuador and Peru.

I made the suggested change in the distribution of Notiomastodon is in South America.

Page 3

Line "(MCNP); one tooth is on display in the Biomuseo, Panama City, Panama; and one tooth is in the vertebrate paleontology collection of the U. S. National Museum of Natural History (USNM)": Number of collection?

I do not quite understand the reviewer's comment above: "(MCNP); one tooth is on display in the Biomuseo, Panama City, Panama; and one tooth is in the vertebrate paleontology collection of the U. S. National Museum of Natural History (USNM)": Number of collection? I'm not sure what the reviewer means by "Number of collection." I assume this means that they want me to include the catalog number of the specimens. I have included the catalog number for each specimen in sections 3.2 and 4.1 , where the localities and dental morphology for each of the Panama gomphothere teeth are described in detail.

Page 8

Line "tooth that could be considered a sixth lophid, but generally are regarded as a partial or half lophid": If there is no interlophid between the fifth lophid and the several small cuspids, this structure can be considered the distal/posterior cingulum.

I changed the description to include reference to the distal/posterior cingulum.

\section{Page 11}

Line "The enamel of this tooth is very thick, from 5 to $6 \mathrm{~mm}$ in thickness": How much is enamel thickness on other molars?

I did not include the enamel thickness for the other three teeth because they are totally unworn, and thus the worn enamel is not exposed and it was not possible to measure the enamel thickness. The only place where the enamel could be measured on these unworn teeth is at the base of the crown, where the enamel meets the broken roots. However, the enamel on most proboscidean teeth, including the Panama Cuvieronius specimens, is extremely thin at the base 
of the crown. Therefore, the enamel thickness measurement at the base of the crown cannot be compared to the enamel thickness on the crown of a worn tooth which is comparatively much thicker.

Page 15

Line "We compared the gomphothere teeth from the Pearl Islands with descriptions and illustrations of upper and lower third molars (M3/m3) of the Quaternary gomphothere Cuvieronius from both the tropical and temperate regions of North America, including specimens from the following localities": I suggest a comparison with the molars of Cuvieronius from Tarija, Bolivia (Boule and Thevenin, 1920; Mothé and Avilla, 2015).

I have added a paragraph providing dental comparisons of the Panama Cuvieronius molars with molars of that genus from Tarija, Bolivia. I also changed the title of section 4.2 to add comparisons with Cuvieronius teeth from South America.

Page 18

Line "Central America. See taxonomic discussion below for our usage of C. hyodon rather than C. tropicus for North American Cuvieronius": What is the variation in the number of cusps in each molar? Mothé and Avilla, 2015, found that South American Cuvieronius has the total number of cusps between 33 to 60, while the expected number is between 40-53. It seems like the molar from south of Isla del Rey, in Figure 2, has more than 60 cusps, and it could be an indication of another taxon (possibly Notiomastodon).

This is a relatively new morphological character for gomphotheres, first introduced by Mothe and Avilla (2015). The method involves the counting of all major and accessory cusps on the third molars of gomphothere teeth. I am not exactly certain of the reviewer's method for counting cusps on a gomphothere tooth. However, I did attempt to count the total number of cusps of the three complete gomphothere teeth from Panama, and briefly discussed this in a new paragraph on page 18 .

I reached the same conclusion as the reviewer did, that the molar from Isla del Rey (Fig. 2) is more complicated that the other two teeth, and could possibly represent Notiomastodon.

Page 20

Line "Cope (1993) later named a second species": Is this year correct? I think it is 1893.

Of course, the reviewer is right. The correct date is 1893. I also mistakenly listed the publication date for this paper in the References as 1993, which has also been changed to 1893.

Page 27

Line "with no records of these two genera from the same site (Ferretti, 2008; Mothé et al., 2013). Cuvieronius is restricted to upland sites in the Andes of western and southern South America, including southern Peru, Bolivia, Chile, and northwestern Argentina": After a detailed 
review from South American specimens, it was possible to identify that Cuvieronius is present in both lowlands and highlands in South America, also, it is not present in Chile and Argentina and it is present in Ecuador. See Mothé and Avilla, 2015.

I amended the discussion of the distribution of Cuvieronius in South America to delete reference to Chile and Argentina and add its presence in Ecuador, and also to note that Cuvieronius is present in both lowland and highland sites.

Page 28

Line "Notiomastodon platensis is found in lowland sites and has a much broader distribution, including Argentina, Uruguay, and Brazil on the Atlantic Coast in eastern South America, coastal Chile, Peru, and Ecuador in western South America, and Colombia and Venezuela in northern South America": Notiomastodon is also present from lowlands to highlands in South America.

Line "The paleoecology of Cuvieronius in North America and South America appears to be quite distinct and somewhat contradictory. Cuvieronius in South America is restricted to highlands in the Andean region, with all known specimens from well south of the equator": There are some records in Ecuador, from Guayllabamba and Baños de Cuenca, Quito Province.

I amended the discussion of the biogeography of Notiomastodon and Cuvieronius in South America to reflect the records mentioned in the previous two paragraphs.

Page 38

Line "Lucas, S. G., Alvarado, G. E., Vega, 1997. The Pleistocene mammals of Costa Rica. Journal of Vertebrate Paleontology 17, 413-427.": I think that Vega is missing the first name.

Corrected. The name is E. Vega.

Page 40

Line "Prado J. L., Alberdi, M. T., Azanza, B., Sánchez, B., Frassinetti, D., 2005.": I think this reference is missing in the text.

A citation to this paper was added on page 28.

Page 44

Line "Figure 1. Map of Panama showing the location of late Pleistocene sites containing the gomphothere Cuvieronius hyodon.": I could not see any dotted line in Figure 1. Could the authors change the size of the line? Also, a scale bar is needed. 
Figure 1 (Map of Panama) was changed to add a scale. Instead of including a dotted line on the map for the edge of the continental shelf, we added a line in the caption stating that the edge of the continental shelf is indicated by the break in slope in the bathymetry of the Gulf of Panama. 